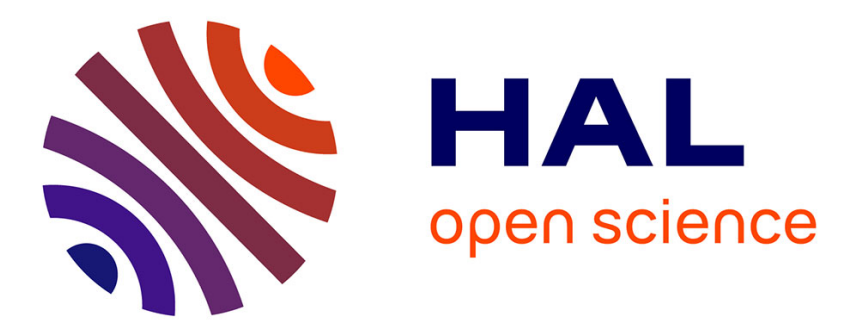

\title{
Effect of Plant Aggregates on Mechanical Properties of Earth Bricks
}

Aurélie Laborel-Préneron, Jean-Emmanuel Aubert, Camille Magniont, Pascale Maillard, C. Poirier

\section{- To cite this version:}

Aurélie Laborel-Préneron, Jean-Emmanuel Aubert, Camille Magniont, Pascale Maillard, C. Poirier. Effect of Plant Aggregates on Mechanical Properties of Earth Bricks. Journal of Materials in Civil Engineering, 2017, 29 (12), 10.1061/(ASCE)MT.1943-5533.0002096 . hal-01876840

\section{HAL Id: hal-01876840 https://hal.science/hal-01876840}

Submitted on 18 Sep 2018

HAL is a multi-disciplinary open access archive for the deposit and dissemination of scientific research documents, whether they are published or not. The documents may come from teaching and research institutions in France or abroad, or from public or private research centers.
L'archive ouverte pluridisciplinaire HAL, est destinée au dépôt et à la diffusion de documents scientifiques de niveau recherche, publiés ou non, émanant des établissements d'enseignement et de recherche français ou étrangers, des laboratoires publics ou privés. 
1 Effect of plant aggregates on mechanical properties of earth bricks

2 A. Laborel-Préneron ${ }^{1 *}$, J-E. Aubert ${ }^{2}$, C. Magniont ${ }^{3}$, P. Maillard ${ }^{4}$, C. Poirier ${ }^{5}$

3

$4{ }^{1}$ LMDC, INSA/UPS Génie Civil, 135 Avenue de Rangueil, 31077 Toulouse cedex

504 France.

$6{ }^{2}$ LMDC, INSA/UPS Génie Civil, 135 Avenue de Rangueil, 31077 Toulouse cedex

704 France.

$8{ }^{3}$ LMDC, INSA/UPS Génie Civil, 135 Avenue de Rangueil, 31077 Toulouse cedex

904 France.

$10{ }^{4}$ Centre Technique de Matériaux Naturels de Construction (CTMNC), Service

11 Céramique R\&D, Ester Technopole, 87069 Limoges Cedex, France

$12{ }^{5}$ Centre Technique de Matériaux Naturels de Construction (CTMNC), Service

13 Céramique R\&D, Ester Technopole, 87069 Limoges Cedex, France

14

15 alaborel@insa-toulouse.fr

16 aubert@insa-toulouse.fr

17 c_magnio@insa-toulouse.fr

18 p.maillard@ctmnc.fr

19 c.poirier@ctmnc.fr

20

21

$22{ }^{*}$ Corresponding author: Aurélie Laborel-Préneron

23 Tel. +33 (0)5 61559926 Fax: 0033 (0)5 615599 49;

24 e-mail: alaborel@insa-toulouse.fr 


\section{Effect of plant aggregates on the mechanical properties of earth bricks}

\section{ABSTRACT}

28 A building material is mainly characterized by its mechanical performance, which

29 provides proof of its quality. However, the measurement of the compressive or

30 flexural strength of an earth-based material with plant aggregates, which is very

31 ductile, is not fully standardised. The objective of this study is to determine the

32 compressive and flexural strengths of a composite made of earth and $0 \%, 3 \%$ or

$336 \%$ of barley straw, hemp shiv or corn cob. Given the manufacturing processes

34 available, cylindrical compressed specimens were studied in compression

35 whereas extruded specimens were studied in flexion. Two protocols were tested

36 for compressive strength measurements: one with direct contact between the

37 specimen and the press, and the other with reduced friction. The test with

38 reduced friction engendered a huge decrease of the stress and a slight decrease

39 of the strain. For both compressive and flexural strengths, the specimens made

40 of earth alone were the most resistant, followed by composites containing straw.

41 The influence of two different treatments applied to the straw is also discussed.

43 Keywords: mechanical properties, earth blocks, straw, hemp shiv, corn cob, 44 extrusion

\section{INTRODUCTION}

47 The building sector is currently innovating in order to use more environmentally

48 friendly materials and to ensure the comfort of users. To this end, it is developing

49 new ecological materials (such as lightweight concrete (Chabannes et al., 2014;

50 Magniont, 2010), or concrete using wastes (Palankar et al., 2015)) but it is also 
51 looking into older, traditional ways, focusing on materials such as earth, stone or 52 wood.

53 Nowadays, around $30 \%$ of the world's population still lives in earth shelters, 54 especially in developing countries (Minke, 2006). Earth is a local resource that is 55 available in abundance and presents many other advantages. This material has 56 low environmental impact because of its recyclability, the little energy needed for 57 the transformation process, the minimal transport required and its energy 58 efficiency. Moreover, it is able to regulate indoor moisture and to improve the 59 comfort of the building's users (Islam and Iwashita, 2006; Minke, 2006).

60 However, earth material presents some weaknesses, such as low mechanical 61 strength, brittleness, hygroscopic shrinkage and limited durability with respect to 62 water (Aymerich et al., 2012; Islam and Iwashita, 2006). In order to reduce these 63 drawbacks, some authors have studied the effect of adding stabilizers such as 64 hydraulic binders and artificial or natural fibres or aggregates (Danso et al., 65 2015a; Laborel-Préneron et al., 2016). The enhancement of soil blocks by 66 stabilizers was reviewed by Danso et al. (Danso et al., 2015a), especially 67 concerning mechanical and water absorption properties. The interest of adding 68 plant aggregates was also highlighted by Laborel-Préneron et al. (Laborel69 Préneron et al., 2016). Based on empirical knowledge, the use of natural fibres 70 and excrement has always helped to improve the properties of earth for building 71 (Chazelles et al., 2011; Millogo et al., 2016). Such additions are now being 72 increasingly studied within an earth matrix because of their apparently huge 73 potential to improve thermal insulation (Bal et al., 2013) and ductility (Mostafa 74 and Uddin, 2015) among other properties.

75 The present paper deals only with the mechanical properties of earth blocks 76 containing plant aggregates. These properties are indeed essential if the material 77 under study is to be used for construction purposes. They will determine whether 
78 it can be used in a load bearing structure or not. However, the mechanical

79 requirements vary from one standard to another, as do the testing procedures,

80 which makes the characterization of this kind of material difficult. In the literature,

81 many studies focus on the influence of plant fibres or aggregates on compressive

82 strength. Twenty-three references investigating compressive strength on this kind

83 of materials are cited in (Laborel-Préneron et al., 2016). Several studies have

84 observed an increase of compressive strength with increasing proportions of

85 plant aggregates such as tea residue (Demir, 2006), sawdust, tobacco residue or

86 grass (Demir, 2008) or cassava peel (Villamizar et al., 2012). However, others

87 have found a decrease in strength: Algin et al. showed a $71 \%$ compressive

88 strength decrease with the addition of $7 \%$ of cotton waste (Algin and Turgut,

89 2008), and a decrease was also observed with straw (Mohamed, 2013) or

90 coconut fibres (Khedari et al., 2005). In some cases, the effect of fibre length was

91 studied. According to Millogo et al. (Millogo et al., 2014, 2015), the compressive

92 strength of the earth composite increased by as much as $16 \%$ with the addition of

93 short Hibiscus Cannabinus fibres $(3 \mathrm{~cm})$ but decreased with long ones $(6 \mathrm{~cm})$,

94 except for a content of $0.4 \%$. An influence of the aspect ratio was also observed

95 by Danso et al. (Danso et al., 2015b) for coconut, bagasse and oil palm fibre, but

96 with an increase of compressive strength as the length of the added fibres

97 increased. None of these studies on earth material with plant aggregates deal

98 with the influence of the testing protocol. However, Morel et al. (Morel et al.,

99 2007) reviewed the various existing protocols for compressive strength testing of

100 blocks of earth alone. Aubert et al. (Aubert et al., 2013, 2015) have discussed the

101 testing of extruded earth blocks, considering the influence of: aspect ratio,

102 confinement (capping with Teflon or not), anisotropy and the mortar joint between

103 two half blocks, on the compressive strength measurement. 
104 Several references focus on the flexural strength of these materials. An increase

105 in flexural strength is observed in most of the studies with an addition of plant

106 aggregates, e.g. Bouhicha et al. (Bouhicha et al., 2005) with barley straw or

107 Aymerich et al. (Aymerich et al., 2012) with wool fibres, but others have observed

108 a decrease, e.g. Villamizar et al. with cassava peels (Villamizar et al., 2012). In all

109 cases, ductility is greatly improved, as the fibre bridging of microcracks prevents

110 them from expanding (Galán-Marín et al., 2010; Mattone, 2005; Mostafa and

111 Uddin, 2015; Segetin et al., 2007).

112 A few, relatively recent, works have investigated the energy absorbed and the

113 mode of failure (Aymerich et al., 2016; Islam and Iwashita, 2006; Lenci et al.,

114 2012; Martins et al., 2014). In flexion, failure usually occurs by fibre gradually

115 slipping from the matrix, leading to both pull out and breaking of the fibres

116 (Mostafa and Uddin, 2015). Some authors have treated the fibres in an attempt to

117 improve the adhesion between the fibre and the matrix and thus enhance the

118 flexural or tensile strength. Some encouraging results have been obtained,

119 notably with acetylation, depending on the temperature of the chemical reaction

120 (Hill et al., 1998), or alkaline treatments on sisal fibres (Alvarez and Vázquez,

121 2006) or banana fibres (Mostafa and Uddin, 2015). However, a linseed oil

122 treatment used by Ledhem et al. on wood shavings gave less promising results,

123 with a decrease in strength, especially in traction.

124 The material studied in this paper is a bio-composite composed of earth and

125 three different plant aggregates: barley straw, hemp shiv and corn cob.

126 Composite specimens were manufactured according two processes:

127 compression or extrusion. After characterization of the earth used, the influence

128 of plant aggregate content on compressive strength and flexural strength was

129 analysed. Compressed specimens were tested in compression following two

130 protocols, one with friction and the other using a system to reduce friction. The 
131 extruded specimens were tested in flexion. The effects of various treatments on

132 barley straw and the effect of its aspect ratio were investigated with this test. The

133 fracture energy developed during the test was also calculated.

135 MATERIALS AND METHODS

\section{Raw materials}

\section{Earth}

138 Earth used in this study was composed of quarry fines from aggregate washing 139 processes (FWAS). These fines, smaller than $0.1 \mathrm{~mm}$, were generated by the 140 washing of limestone aggregates produced for the chemical or concrete industry. 141 The sludge created was left to dry in sedimentation basins and was then reduced 142 to powder to be used in different applications.

\section{$144 \quad$ Plant aggregates}

145 Three types of plant aggregates were used in this study: barley straw (two 146 different lengths), hemp shiv and corn cob. Barley Straw (S) is the part of cereal's 147 stem rejected during the harvest. Hemp shiv $(H)$ is the by-product of the hemp 148 defibration process and corresponds to the lignin-rich part of the stem. Corn Cob 149 (CC) is the central part of the ear of corn cleared of grain and crushed. The 150 hardest part was studied here. The physical and chemical characteristics of these 151 plant aggregates were determined in (Laborel-Préneron et al., 2017) and are 152 recapitulated in Table 1. However, the previous characterization was done only 153 for the shortest straw $\left(S_{\text {short }}\right)$, of average length $8 \mathrm{~mm}$. In the present study, the 154 longest straw $\left(S_{\text {long }}\right)$, of average length $15 \mathrm{~mm}$, was used only for the flexural 155 strength test.

\section{Insert Table 1 here}

157 Surfactant additives 
158 In agriculture, the efficiency of crop protection products can be improved by the

159 addition of surfactants that increase the absorption of the product on the plants.

160 These additives can optimize spreading and reduce negative effects such as drift

161 and run off. In this study, the objective of using these surfactants was to increase

162 the adhesion between the plant aggregates and the earth matrix by reducing the

163 surface tension of the mixing water. Two types of surfactant additives were

164 tested: A1, which was soya lecithin based, and A2, which was latex based. They

165 were both applied to the long straw only.

166 To apply the surfactants to the straw, the particles were immersed for 1 hour in 167 the additive, diluted at the rate recommended by the supplier: $0.5 \%$ of the water 168 volume for $\mathrm{A} 1$ and $0.1 \%$ for $\mathrm{A} 2$. The straw was then sieved to remove extra water 169 before being dried at $30^{\circ} \mathrm{C}$ in an oven.

171 Physical, chemical and mineralogical characterization of FWAS

172 Particle size distribution and Atterberg limits

173 The size distribution was determined by sedimentation after wet sieving at $80 \mu \mathrm{m}$, 174 according to standard NF P94-057 (AFNOR, 1992). The geotechnical 175 characteristics were evaluated using the Atterberg limits, according to standard 176 NF P 94-051 (AFNOR, 1993).

178 Chemical and mineralogical composition

179 X-ray diffraction on a sample crushed to a size of less than $80 \mu \mathrm{m}$ was carried 180 out with a Siemens D5000 powder X-ray diffractometer equipped with a 181 monochromator having a Ka $(\lambda=1.789 \AA)$ cobalt anticathode. Thermal 182 mineralogical characterization was also performed by thermal gravimetric 183 analysis $(\mathrm{TGA})$ of a crushed sample $(<80 \mu \mathrm{m})$ heated to $1050^{\circ} \mathrm{C}$ at a constant 184 rate of $10^{\circ} \mathrm{C} \cdot \mathrm{min}^{-1}$. Major oxide composition was evaluated on the basis of 
185 macroelemental analysis performed by Inductively Coupled Plasma-Atomic

186 Emission Spectrometry (ICP-AES) on crushed samples smaller than $80 \mu \mathrm{m}$. The

187 mineral composition was determined from X-ray diffraction results and the

188 chemical composition.

189

190 Manufacturing process

191 Specimens for the different tests were prepared by two manufacturing processes:

192 one using static compression and the other using extrusion. The proportion of

193 plant aggregates was expressed by dry weight content, according to formula (1):

$$
\text { Ag. content }=\frac{m_{A g}}{m_{A g}+m_{F W A S}} \times 100
$$

194 where Ag. content is the plant aggregate content in $\%, \mathrm{~m}_{\mathrm{Ag}}$ is the dry mass of 195 plant aggregates and $\mathrm{m}_{\mathrm{FWAS}}$ is the dry mass of earth.

197 Compressed specimens

198 Various mixtures were prepared to make the specimens: FWAS only and 199 mixtures containing one of the plant aggregates in a proportion of $3 \%$ or $6 \%$. The 200 water contents of the mixtures were determined by the Proctor test, and then 201 rounded up because, according to Minke (Minke, 2006), this is a minimum value 202 for manufacturing compressed earth bricks. 
203 Table 2 recapitulates the different mixture proportions and the dry densities of the

204 specimens obtained (average of six specimens). As expected, the water content 205 of the dry mass needed to make the mixtures increased when the plant 206 aggregate content increased. It was higher for straw than for hemp and corn cob 207 because straw particles have a higher water absorption coefficient than the other 208 two aggregates ( $414 \%$ vs. $380 \%$ for hemp and $123 \%$ for corn cob) (Laborel209 Préneron et al., 2017).

210 Insert table 2 here

212 To manufacture the specimens, the earth and plant aggregate fractions were 213 poured into a blender and mixed by hand. Then, water was added and the 214 materials were mixed mechanically until a homogeneous mix was obtained. The 215 raw materials were mixed the day before moulding.

216 Cylindrical specimens $5 \mathrm{~cm}$ in diameter and $5 \mathrm{~cm}$ high (Ф5H5), intended for 217 compressive strength tests, were manufactured by double static compression at 218 the Proctor density. After demoulding, the height of the specimens containing 219 barley straw and hemp shiv increased significantly due to the high compressibility 220 of the plant aggregates. This increase reached $10 \%$ of the height for an addition 221 of $6 \%$ of hemp shiv, for example. This expansion led to the formation of 222 distributed cracks, specifically in the case of an addition of $6 \%$ of straw (Figure 1). 223 The specimens were first dried at $40^{\circ} \mathrm{C}$ for 24 hours, then the temperature was 224 increased by $0.1^{\circ} \mathrm{C} / \mathrm{min}$ to $100^{\circ} \mathrm{C}$ and kept at $100^{\circ} \mathrm{C}$ until the weight became 225 constant (weight variation less than $0.1 \%$ between two weighings 24 hours 226 apart). This rise in temperature was carried out slowly to keep shrinking 227 homogeneous and to avoid mechanical stresses. The specimens were then 228 stored in a room regulated at $20^{\circ} \mathrm{C}$ and $50 \%$ relative humidity $(\mathrm{RH})$ and were 
229 tested when they were in equilibrium with the environment (about one week 230 later).

231 Figure 1. Compressed specimens of FWAS (a) and S6 (b)

232 Extruded specimens

233 Six types of specimens were prepared: specimens made with FWAS only (i), and 234 specimens made with $3 \%$ of short straw (ii), long straw (iii), hemp shiv (iv), long 235 straw treated with the A1 surfactant (v), or long straw treated with the A2 236 surfactant (vi). Corn cob was not tested in extrusion because of the poor 237 distribution of the particles observed in a preliminary trial and its low strength in 238 compression. To manufacture these specimens, earth and plant aggregate 239 fractions were poured into a blender and were mixed by hand. Then, the 240 materials were mixed mechanically in the blender and water was added 241 progressively until the consistency of the mixture was sufficiently homogeneous 242 and plastic to be extruded. The details of the mixes are recapitulated in 


\section{Table 3.}

\section{Insert table 3 here}

246

247 The specimens were manufactured with a medium sized laboratory extruder. The 248 mixture was extruded under vacuum through a $7 \mathrm{~cm} \times 3.5 \mathrm{~cm}$ die (Figure 2). The 249 specimens were difficult to cut in the fresh state because of the presence of plant 250 particles. They were therefore air-dried until the weight become constant (weight 251 variation of less than $0.1 \%$ between two weighings 24 hours apart) and then cut 252 to a length of $18 \mathrm{~cm}$ with a circular saw. Treatment of the straw did not modify the 253 dry density of the composites. However, when the two manufacturing processes 254 were compared ( 
255 Table 2 and

256 
257 Table 3), an increase of density was observed for the extruded specimens

258 containing plant aggregates. It was due to the extrusion of the material under

259 vacuum, which reduced porosity, and to the extrusion pressure due to the worm 260 screw.

261 Figure 2. Vacuum extruder

262 Compressive strength test

263 The compressive strength tests on the $Ф 5 \mathrm{H} 5$ specimens were performed using a

$264100 \mathrm{kN}$ capacity hydraulic press. The load was applied at a constant deflection

265 rate of $3 \mathrm{~mm} \cdot \mathrm{min}^{-1}$. This speed was chosen as an intermediate value between the

$2661.2 \mathrm{~mm} \cdot \mathrm{min}^{-1}$ specified in the French standard XP P 13-901 (AFNOR, 2001)

267 (intended for compressed earth blocks) and the $5 \mathrm{~mm} \cdot \mathrm{min}^{-1}$ used by Cerezo

268 (Cerezo, 2005) (intended for hemp concrete). Three specimens of each mixture

269 were tested in two different tests: one test with the specimen in direct contact with

270 the steel plates (generating friction) and the other including a system avoiding

271 friction (Figure 3) as described by Olivier et al. (Olivier et al., 1997). In the latter

272 case, a 2-mm-thick piece of Teflon and a thin neoprene sheet - with a drop of oil

273 between the layers - were placed between the earth specimen and the steel

274 (neoprene in contact with the specimen, and Teflon in contact with the steel).

275 Teflon was used because of its low friction coefficient and neoprene because of

276 its high mechanical resistance. Displacements and loads were measured in each

277 case. The Young's modulus of each specimen was then calculated from the

278 linear part of the stress-strain curve.

279 Figure 3. Compressive test method: (a) with friction and (b) with reduced 280 friction

$281 \quad$ Flexural strength test

282 The flexural strength tests on the extruded specimens were performed using a $283100 \mathrm{kN}$ capacity hydraulic press with a $10 \mathrm{kN}$ sensor. The load was applied at a 
284 constant deflection rate of $1 \mathrm{~mm} \cdot \mathrm{min}^{-1}$ as was done by Aymerich et al. (Aymerich

285 et al., 2012). The samples were loaded under three point loading conditions with 286 the lower supports placed $10 \mathrm{~cm}$ apart, corresponding to the value given in the 287 French standard NF EN 196-1 intended for cements (AFNOR, 2006). 288 Measurements were made in triplicate.

289 This test was carried out in order to study the effect of the plant aggregate 290 addition on ductility. According to the literature, this kind of addition has a marked 291 effect on ductility (Aymerich et al., 2012; Bouhicha et al., 2005; Galán-Marín et 292 al., 2010; Ghavami et al., 1999). Deflection was measured from bottom to top on 293 an aluminium platelet glued in the middle of the sample, as can be seen on 294 Figure 4. The test was stopped for a deflection close to $3 \mathrm{~mm}$, the limit of the 295 sensor stroke.

\section{Figure 4. Flexural test set up}

298 In order to compare the flexural strength with values reported in the literature or 299 values from standards, the bending stress was calculated only at failure with the 300 beam theory. Considering that classical hypotheses of solid mechanics applied 301 and that the section was not cracked until peak load (elastic part of the curve) 302 (Lenci et al., 2012; Mostafa and Uddin, 2015), the stress $\sigma(\mathrm{MPa})$ was calculated 303 from the following expression (2):

$$
\sigma=\frac{3 F L}{2 b h^{2}}
$$

304 with $F$ the maximum load at failure $(N), L$ the distance between the supports $305(\mathrm{~mm}), \mathrm{b}$ the width $(\mathrm{mm})$ and $\mathrm{h}$ the height $(\mathrm{mm})$ of the sample.

307 To determine the effect of the plant aggregate on the behaviour at failure and 308 post-peak, the fracture energy $\left(G_{f}\right)$ was calculated. It provided information about 
309 the amount of energy absorbed when the specimen was broken into two parts. It

310 was represented by the area under the load-displacement curve divided by the

311 projected fracture area (Guinea et al., 1992). Usually, it is measured on notched

312 samples (Aymerich et al., 2012, 2016; Guinea et al., 1992), so the whole load-

313 displacement curve is considered. However, as the samples did not have a

314 notch, the area was taken into account from the failure point and to a deflection

315 of $3 \mathrm{~mm}$. The fracture energy was calculated from the expression (3):

$$
G_{f}=\frac{\int_{\delta_{f}}^{\delta_{3 m m}} F(\delta)}{S}
$$

316 where $\delta_{f}$ is the deflection at failure $(m), F$ is the load $(N)$ and $S$ is the initial 317 section $\left(\mathrm{m}^{2}\right)$.

318 The Young's modulus of each specimen was then calculated from the linear part

319 of the stress-strain curve.

320

321 RESULTS AND DISCUSSION

322 Characterization of earth

323 Particle size distribution and Atterberg limits

324 The particle size distribution is presented in Figure 5 and compared with the size 325 distribution recommended for compressed earth blocks (CEB) in the XP 13-901 326 standard (AFNOR, 2001).

327 Figure 5. Comparative grain size distribution curve for earth: FWAS and 328 standard

329 The earth was extremely fine: $99 \%$ of the particles were smaller than $80 \mu \mathrm{m}$ and 330 the average particle size (D50) determined using the pipette analysis was 6.5 $331 \mu \mathrm{m}$. The curve did not fit the limits recommended by the standard, the passing 332 mass being higher for each grain size. Atterberg limits were equal to $30 \%$ for the 333 liquid limit, $21 \%$ for the plastic limit and $9 \%$ for the plasticity index. The plasticity 
334 of this material was not located in the spindle of the diagram recommended by

335 the XP 13-901 standard (AFNOR, 2001). However, even though the size

336 distribution and Atterberg limits did not meet the recommended criteria, it was

337 already shown that it was possible to manufacture CEBs with a huge variety of

338 earths (Aubert et al., 2014; Laborel-Préneron et al., 2016).

340 Chemical and mineralogical composition

341 The X-ray diffractogram is presented on Figure 6. This diagram reveals the large 342 presence of calcite $\left(\mathrm{CaCO}_{3}\right)$ and shows the presence of other minerals in smaller 343 quantities: kaolinite $\left(\mathrm{Al}_{2} \mathrm{Si}_{2} \mathrm{O}_{5}(\mathrm{OH})_{4}\right)$, quartz $\left(\mathrm{SiO}_{2}\right)$, illite $\left(\mathrm{KAl}_{2}\left(\mathrm{AlSi}_{3}\right) \mathrm{O}_{10}(\mathrm{OH})_{2}\right)$, 344 goethite $(\mathrm{FeO}(\mathrm{OH}))$ and dolomite $\left(\mathrm{CaMg}\left(\mathrm{CO}_{3}\right)_{2}\right)$.

345 Figure 6. X-ray diffraction pattern of the earth. (c) calcite, (d) dolomite, (g) 346 goethite, (i) illite, (k) kaolinite, (q) quartz

347 To complete its mineralogical characterization, the earth was subjected to 348 thermal gravimetric analysis, the results of which are presented in Figure 7. The 349 loss of mass around $105^{\circ} \mathrm{C}$ was due to the evaporation of water and that around $350540^{\circ} \mathrm{C}$ indicated the removal of the constituting water, which led to the 351 transformation of kaolinite into metakaolinite (Kornmann and Lafaurie, 2005). The

352 greatest loss of weight, of about $25 \%$, occurred around $910^{\circ} \mathrm{C}$ and was due to the 353 decarbonation of calcite and dolomite.

354 Figure 7. TG and DTG (Derivative Thermo-Gravimetric) curves of the earth

355 The chemical composition of the earth is given in 
356 Table 4, where a large amount of calcium is noticeable. Using the chemical 357 composition and the mineral characterization, it is possible to estimate the 358 proportion of each mineral. The fines used were thus composed for $60 \%$ of 359 calcite, $11 \%$ of kaolinite, $11 \%$ of illite, $10 \%$ of quartz, $6 \%$ of dolomite and $3 \%$ of 360 goethite.

$361 \quad$ Insert table 4 here

362

363 Compressive strength measured on compressed specimens

364 The average over three specimens of dry density, maximum compressive 365 strength and other mechanical properties of each mixture and for each testing 366 protocol are reported in 
367 Table 5. The compressive strength value required by the New-Zealand Earth

368 Building standard NZS 4298 (NZS 4298) is 1.3 MPa. This value was reached for 369 all the mixtures of this study, for both protocols, except for CC6 tested with 370 reduced friction $(0.9 \mathrm{MPa})$.

$371 \quad$ Insert table 5 here

372 Influence of plant aggregate type and content on the bulk density

373 A number of authors have shown that bulk density is influenced by the addition of 374 plant aggregates (Algin and Turgut, 2008; Demir, 2008; Khedari et al., 2005). The 375 bulk density of each mixture used here is plotted on Figure 8. As expected, bulk 376 density decreased as the aggregate content increased for the three kinds of plant 377 aggregates. However, some differences between the mixtures with straw or 378 hemp and the mixture with corn cob can be noted. Bulk density was higher for the 379 mixtures with corn cob than for those with straw or hemp. This difference may 380 have been due to the huge variability of the particle bulk densities: $497 \mathrm{~kg} \cdot \mathrm{m}^{-3}$ for 381 corn cob against $57 \mathrm{~kg} \cdot \mathrm{m}^{-3}$ and $153 \mathrm{~kg} \cdot \mathrm{m}^{-3}$ for straw and hemp shiv, respectively 382 (Laborel-Préneron et al., 2017).

383 Figure 8. Bulk density as a function of the plant aggregate content

384 Influence of the testing protocol on compressive strength

385 Usually, only the compressive test with friction is performed ((Galán-Marín et al., 386 2010; Mohamed, 2013; Villamizar et al., 2012)) and follows standards ASTM 387 D2166 (ASTM D 2166, 2004), XP P 13-901 (AFNOR, 2001) or TS EN 772-1 (TS 388 EN 772-1, 2002). However some authors have also measured the strength with 389 lower friction (using a layer of sand and a transparent film on either side of the 390 sample (Piattoni et al., 2011; Quagliarini and Lenci, 2010) or with Teflon (Aubert 391 et al., 2015)) to obtain the "real" compressive strength. Both methods, with 392 friction and with Teflon reducing friction, were carried out to see what difference 393 was actually observed. The results are shown in Figure 9. 
394 Figure 9. Compressive strength of the mixtures according to the testing

395 protocol

396 For each composition, the compressive strength measured in the tests with 397 friction was greater than that found in tests with reduced friction because of the 398 confinement (transverse displacements not allowed at the ends of the 399 specimens). In the case of earth alone (FWAS) and S6 specimens, the decrease

400 in strength between the protocols was only about 3 to $5 \%$, whereas it reached 401 between $28 \%(\mathrm{C} 6)$ and $59 \%$ (CC3) for the other mixtures. In some cases (FWAS 402 or CC6), standard deviation was quite high. In the case of CC6, for example, this 403 large variability of the results was due to one specimen having significantly higher 404 strength than the other two - probably because of the heterogeneity of the 405 material (Aubert et al., 2015), with a poor distribution of the corn cob granules.

406 The results of $\mathrm{H} 3, \mathrm{H} 6, \mathrm{CC} 3$ and $\mathrm{CC} 6$ measured with reduced friction are very

407 close; it is thus difficult to establish the highest strength with this protocol.

408 Unlike Aubert et al.'s finding (Aubert et al., 2015) that the strength decreased by 409 only $10 \%$ with the use of Teflon capping, the choice of the method was observed 410 to significantly affect the strength value measured here. It is thus important to 411 choose the most adequate method. In order to allow comparisons among 412 samples, and with the literature, only the values obtained with friction were kept 413 here. This protocol was also easier to set up and more similar to the behaviour of 414 a brick within a wall, with friction between the bricks.

416 Effect of the plant aggregates on compressive strength

417 The compressive strengths of the specimens are summarized in Figure 10 for the 418 different plant aggregate types and contents when the protocol with friction at the 419 interface between the specimen and the press was employed. 
420 The compressive strength of the specimen composed of earth alone is higher

421 than that of all the others, which is in accordance with the density values of the 422 various specimens. Its average strength of $4.0 \mathrm{MPa}$ is higher than the typical 423 value for CEBs which is, according to Morel et al. (Morel et al., 2007), between 2 424 and $3 \mathrm{MPa}$. Furthermore, a decrease in compressive strength is noticeable when 425 hemp shiv and corn cob contents increase. The values are 2.4 and $1.8 \mathrm{MPa}$ for $426 \mathrm{H} 3$ and $\mathrm{H} 6$, and 3.2 and $1.8 \mathrm{MPa}$ for $\mathrm{CC} 3$ and $\mathrm{CC} 6$ specimens. This reduction, 427 linked to the incorporation of particles with low compressive strength and 428 stiffness, can be correlated to the decrease in bulk density observed with the 429 addition of plant aggregate (Al Rim et al., 1999; Ghavami et al., 1999). In the 430 case of barley straw, the average strengths are 3.3 MPa and 3.8 MPa for S3 and 431 S6 respectively. The ultimate compressive strength of S6 specimens is thus 432 higher than that of S3 specimens. This can be explained by a consolidation 433 phenomenon due to the high compressibility of the straw that allows its porosity 434 to decrease as strain increases. This phenomenon is not observed for $\mathrm{H} 6$ or CC6 435 specimens because of the lower ductility of hemp and corn aggregates. This 436 difference could also be due to the different shapes of the particles, straw being 437 more elongated than hemp shiv (Laborel-Préneron et al., 2017). This kind of 438 result was also observed by Millogo et al. (Millogo et al., 2014) for the longest 439 fibres but for smaller quantities (less than 1\%). This observation was explained 440 by the limitation of crack opening by the fibres.

\section{$441 \quad$ Figure 10. Results for compressive strength test with friction}

442 Effect of the plant aggregates on ductility

443 Figure 11 shows the stress-strain curves of all the specimens. It can be noted 444 that FWAS specimens show brittle failure whereas the ultimate strain is high for 445 the specimens containing plant aggregates, especially those with $6 \%$. Their peak 446 strain is, on average, $19.9,10.7$ and $2.5 \%$ for S6, H6 and CC6, respectively, 
447 whereas it is only $1.3 \%$ for FWAS. Although these specimens are weaker than

448 FWAS specimens, they are also more ductile, with a larger zone of plasticity.

449 Ductility of the composite is thus increased by the addition of plant aggregates.

450 However, in calculating building structures, such deformations of the material

451 cannot be tolerated.

452 In order to make comparisons among the materials and to maintain a strain level

453 compatible with the intended use, we chose to limit the strain to $1.5 \%$ and to keep

454 the corresponding compressive strength value, as described by Cerezo (Cerezo,

455 2005) for hemp concrete. The maximum compressive strength was kept in cases

456 when the failure occurred before $1.5 \%$ strain (which only concerned FWAS

457 specimens).

458 These values are compared with the values at failure in Figure 12. For a given

459 deformation, compressive strength is higher for FWAS specimens. The values

460 are far below the maximum compressive strength and do not reach $1 \mathrm{MPa}$ for the

461 specimens with straw or hemp shiv whereas the compressive strength is above

462 the limit of $1.3 \mathrm{MPa}$ in the case of corn cob. In the cases where the materials do

463 not have the strength required to be used as bearing structures, they can be

464 used as infill material in a wood structure or as a partition wall, for instance.

465 Figure 11. Strain-stress diagram for all the specimens

466 Figure 12. Maximum compressive strength $\left(\sigma_{c}\right)$ and compressive strength

467 at $1.5 \%$ strain $\left(\sigma_{c, 1.5} \%\right)$

468 Influence of the testing protocol on Young's modulus

469 Young's moduli were obtained from compressive strength tests and are 470 recapitulated in Figure 13, according to the testing protocol. Friction does not 471 seem to have any great influence on the modulus, which is of the same order of 472 magnitude for both situations (with quite large standard deviations). The most 
473 striking result visible in the figure is that the Young's modulus of FWAS

474 specimens is the highest (around $500 \mathrm{MPa}$ ).

475 Figure 13. Young's moduli of the materials for both protocols

476 Effect of the plant aggregates on Young's modulus

477 The Young's modulus obtained from the tests with friction is represented 478 according to the plant aggregate content in Figure 14. The Young's moduli of the 479 specimens containing $3 \%$ of barley straw, hemp shiv and corn cob are 480 respectively 62,75 and $217 \mathrm{MPa}$. For an addition of $6 \%$, the moduli are 31,26 481 and $102 \mathrm{MPa}$ respectively for barley straw, hemp shiv and corn cob. Specimens 482 made with straw and with hemp shiv showed very similar stiffness for a given 483 content. With a modulus of $439 \mathrm{MPa}$, FWAS specimens had the highest stiffness.

484 For an increase of each plant aggregate content, there was a decrease in the 485 Young's modulus. This result can be explained by the high compressibility of the 486 plant particles (Cerezo, 2005) and is in agreement with various references (Al 487 Rim et al., 1999; Chee-Ming, 2011; Piattoni et al., 2011; Quagliarini and Lenci, 488 2010) stating that the straw addition controls the plastic behaviour of the 489 specimen through a lower homogeneity of the mixture. This decrease of Young's 490 modulus could be linked with the density of the specimens as shown in Figure 15. 491 An empiric exponential correlation between Young's modulus and dry density is 492 found: $E=0.3184 \exp \left(0.0035 \rho_{d r y}\right)$ with $\rho_{\text {dry }}$ in $\mathrm{kg} \cdot \mathrm{m}^{-3}$. Such a relation has 493 already been proposed by Al Rim et al. for earth specimens with wood 494 aggregates (Al Rim et al., 1999), but it was $E=1127 d^{3.142}$ with $\mathrm{d}$ the density of 495 the dry material relative to the density of water.

496 Figure 14. Young's modulus from compressive test as a function of the 497 plant aggregate content

498 Figure 15. Young's modulus as a function of the density 
499 Flexural strength measured on extruded specimens

500 The average of dry density, the maximum flexural strength and other mechanical 501 parameters are reported in

502 
503 Table 6. The minimum flexural tensile stress required by the Masonry Standards

504 Joint Committee (MSJC) (Masonry Standards Joint Committee (MSJC), 2008)

505 (quoted in (Villamizar et al., 2012)) for clay and concrete blocks is $0.21 \mathrm{MPa}$.

506 Another value, of $0.65 \mathrm{MPa}$, is required by the British Standard BS 6073 (BS

5076073,1981 ) (quoted in (Algin and Turgut, 2008)) for building materials to be used

508 in structural applications. All the flexural strengths of the specimens tested in this

509 study are above these two minimum requirements, the lowest strength being 1.34

$510 \mathrm{MPa}$, found for $\mathrm{H} 3$ specimens.

\section{Insert table 6 here}

512 Effect of the plant aggregate type on the flexural strength

513 The maximum flexural strengths of the different mixtures are represented in

514 Figure 16 (a). FWAS has the highest flexural strength, followed by $\mathrm{S}_{\text {short }}, \mathrm{S} 3_{\text {long }}$

515 and $\mathrm{H} 3$, with values of 2053, 1900, 1776 and $1453 \mathrm{~N}$ respectively. This result

516 could be correlated with the respective densities: the lower the density, the lower

517 the flexural strength.

518 It can be seen that the flexural strength is higher for the specimens with short

519 straw than for those with long straw. This result is contrary to the findings of some

520 other authors (Danso et al., 2015b; Mostafa and Uddin, 2015), who stated that an

521 increase of the fibre length increased the embedded length and thus the

522 adhesion area, leading to an improvement in flexural strength. This result could

523 be explained by the fact that, for the same straw content, there are more particles

524 in a mix with short straw than with long straw, engendering a better distribution of

525 the particles in the matrix. Another explanation could be the existence of a length

526 limit, depending on the specimen size, above which the difficulty of dispersion

527 offsets the positive effect of the reinforcement. Moreover, after being extruded

528 under vacuum, the specimens with short straw presented a better visual surface 
529 quality than the specimens with long straw. This could lead to a better adhesion

530 between the earth and the straw, explaining the higher resistance.

531 Although most cases in the literature show an increase in flexural strength with

532 an addition of plant aggregate ((Al Rim et al., 1999; Aymerich et al., 2012;

533 Bouhicha et al., 2005; Galán-Marín et al., 2010)), an adverse effect (decrease of

534 flexural strength) was found by Villamizar et al. (Villamizar et al., 2012) with an

535 addition of cassava peels and by Algin and Turgut (Algin and Turgut, 2008) with

536 an addition of cotton wastes. This could be due to the heterogeneity of the

537 material or the weakness of the adhesion between the particles and the matrix

538 (Yetgin et al., 2008).

539 Figure 16. Influence of the plant aggregate on flexural behaviour: (a)

540 Flexural load-carrying capacity, (b) Peak strain ( $\left.\varepsilon_{f}\right)$, (c) Average fracture

541 energy $\left(G_{f}\right)$ and $(d)$ Young's modulus

542 Effect of the plant aggregate type on ductility and Young's modulus

543 At the end of the tests, reinforced specimens were not totally split into two parts

544 (Figure 4) and extra manual force was necessary to separate them, whereas

545 FWAS specimens were divided into two parts. Figure 17 presents typical load-

546 deflection curves obtained during the bending test for the different samples.

547 These curves clearly show that the addition of plant aggregates increases the

548 ductility, increasing the deflection at failure and giving some residual strength.

549 Peak strain is represented in Figure 16 (b). As mentioned above, the strain is

550 increased with the addition of plant aggregates, especially for long particles. The

551 strain was 0.44 and $0.55 \%$ respectively for short and long straw. The lower value

552 in the case of hemp shiv $(0.31 \%)$ could be attributed to a morphological effect:

553 the particle is indeed less elongated and so does not have as much surface area

554 in contact with the earth matrix as the straw particle. 
555 Figure 16 (c) represents the average fracture energy for each composition. The

556 value is close to $0 \mathrm{J.m}^{-2}$ for the FWAS specimens whereas the fracture energy of

557 the other specimens is higher: 296,484 and $157 \mathrm{J.m}^{-2}$ respectively for $\mathrm{S}_{\text {short }}$

$558 \mathrm{~S}_{\text {long }}$ and $\mathrm{H} 3$. The addition of plant aggregates allows a huge increase in fracture

559 energy. The energy absorbed increases when the length of the fibre increases; it

560 is $39 \%$ higher with long than short straw, meaning that its residual strength is

561 greater. This result shows that the fracture response of materials reinforced with

562 plant aggregates or fibres is governed by mechanisms of toughening such as

563 fibre bridging and fibre pull-out (Aymerich et al., 2016). These effects occur only

564 for sufficient crack opening.

565 Figure 17. Typical load-deflection curves

566 The experimental values of Young's moduli are presented in Figure 16 (d). As for

567 the elastic moduli from the compressive test, they seem to decrease with the

568 addition of plant aggregates.

569 This result is partially correlated with the literature. Although the flexural Young's

570 modulus of an earth material with wood aggregates increased with between 10

571 and $20 \%$ of addition, it decreased above $20 \%$ (Al Rim et al., 1999).

572 Effect of the surfactant on the flexural strength, post-peak behaviour and Young's

573 modulus

574 The behaviour under flexion of the mixtures with untreated and treated long straw

575 is represented on Figure 18. The increase in flexural load capacity between $S_{A 2}$

576 and $\mathrm{S} 3_{\text {long }}$ is only about $3 \%$ and the standard deviations are high. The surfactant

577 has no effect on the flexural strength.

578 Peak strain is represented in Figure 18 (b). The strain decreases with the addition

579 of a surfactant, especially the A2 additive. Strain is $0.55,0.49$ and $0.36 \%$ for

$580 \quad S 3_{\text {long }}, S_{A 1}$ and $S_{A 2}$ respectively. 
581 Figure 18 (c) represents also the average fracture energy for the untreated and

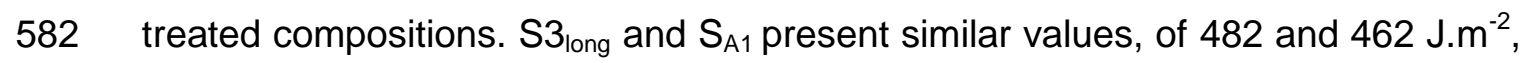
583 respectively but a small increase of $10 \%$ can be noticed for $S_{A 2}$, with a fracture 584 energy of $538 \mathrm{~J} . \mathrm{m}^{-2}$.

585 Experimental values of Young's moduli are presented in the Figure 18 (d). The 586 elastic modulus is higher for the treated specimens, with values of 442 and 508

$587 \mathrm{MPa}$ for $\mathrm{S}_{\mathrm{A} 1}$ and $\mathrm{S}_{\mathrm{A} 2}$, respectively, whereas it is only $385 \mathrm{MPa}$ for $\mathrm{S} 3_{\text {long }}$. The $\mathrm{A} 2$ 588 additive again seems to be the more efficient of the two surfactants tested here, 589 giving an increase in stiffness of about $24 \%$.

590 Even though the flexural strength is not increased by the straw treatment, the 591 stiffness of the material seems to be increased and the adhesion between the 592 straw and the matrix should also be improved. Surfactant A2 seems to have a 593 greater effect than A1. However, this is a preliminary study, which needs to be 594 pursued further, in particular to optimize various parameters such as the dilution 595 ratio, application method and drying temperature.

596 Figure 18. Influence of the surfactants on flexural behaviour: (a) Flexural 597 load-carrying capacity, (b) Peak strain $\left(\varepsilon_{f}\right)$, (c) Average fracture energy $\left(G_{f}\right)$ 598 and (d) Young's modulus

600 CONCLUSION

601 The mechanical properties of compressed and extruded earth-based specimens 602 were tested. These two ways of manufacturing led to different densities for the 603 same formulation. However, compressive and flexural measurements were 604 independent. Several main conclusions can be drawn concerning the influence of 605 the various parameters such as the plant aggregate type, the protocol of the test 606 or possible treatment. Concerning the compressive tests, the measurement with 607 reduced friction gave a lower compressive strength and peak strain. This method 
608 gives a more "realistic" resistance, but is still little used in the literature. At

609 rupture, strength was higher in the case of straw addition, followed by hemp shiv

610 and corn cob additions. For both compressive and flexural tests, the addition of

611 plant aggregates decreased the strength but improved the ductility of the

612 material, decreasing the Young's modulus. Concerning flexural strength, a better

613 resistance was observed for short than for long straw, but a higher strain was

614 noted for the longest straw. Strain at peak was lower when the straw was treated

615 with the A2 additive, but with the flexural strength was the same.

616 Various works have shown the diversity of mechanical tests existing for earth

617 bricks and these should be harmonized by means of more investigation and

618 standardization. However, the testing of bio-based earth materials should not be

619 forgotten as their behaviour is much more ductile and cannot be tested in the

620 same way. Although the treatment with surfactants did not improve the

621 mechanical strength of the composites, it did cause a slight decrease in the strain

622 at rupture. More investigation is thus required to optimize its effect on strength, in

623 particular concerning the treatment process (the dilution rate and details of the

624 straw treatment method). In this work, compressed specimens were used to

625 study the influence of plant aggregates and surfactant additives during

626 compression tests whereas extruded specimens were tested in flexion. However,

627 in further work it would be interesting to determine whether or not the adhesion

628 between earth and fibre differs according to the process used: compression or 629 extrusion.

630

631 ACKNOWLEDGEMENTS

632 The authors wish to thank the French National Research Agency - France (ANR)

633 for funding project BIOTERRA - ANR - 13 - VBDU - 0005 Villes et Bâtiments 634 Durables. 
636 REFERENCES

637 AFNOR (1992). NF P94-057 - Analyse granulométrique des sols - Méthode par

638 sédimentation.

639 AFNOR (1993). NF P94-051 - Détermination des limites d'Atterberg - Limite de

640 liquidité à la coupelle - Limite de plasticité au rouleau.

641 AFNOR (2001). Blocs de terre comprimée pour murs et cloisons: définitions -

642 spécifications - méthode d'essais - condition de réception.

643 AFNOR (2006). Méthode d'essais des ciments - Détermination des résistances 644 mécaniques.

645 Al Rim, K., Ledhem, A., Douzane, O., Dheilly, R.M., and Queneudec, M. (1999).

646 Influence of the proportion of wood on the thermal and mechanical performances

647 of clay-cement-wood composites. Cem. Concr. Compos. 21, 269-276.

648 Algin, H.M., and Turgut, P. (2008). Cotton and limestone powder wastes as brick

649 material. Constr. Build. Mater. 22, 1074-1080.

650 Alvarez, V.A., and Vázquez, A. (2006). Influence of fiber chemical modification

651 procedure on the mechanical properties and water absorption of MaterBi-Y/sisal

652 fiber composites. Compos. Part Appl. Sci. Manuf. 37, 1672-1680.

653 ASTM D 2166 (2004). Standard test method for unconfined compressive strength 654 of cohesive soil.

655 Aubert, J.E., Fabbri, A., Morel, J.C., and Maillard, P. (2013). An earth block with a 656 compressive strength higher than $45 \mathrm{MPa}$ ! Constr. Build. Mater. 47, 366-369. 
657 Aubert, J.-E., Marcom, A., Oliva, P., and Segui, P. (2014). Chequered earth

658 construction in south-western France. J. Cult. Herit. 16, 293-298.

659 Aubert, J.E., Maillard, P., Morel, J.C., and Al Rafii, M. (2015). Towards a simple 660 compressive strength test for earth bricks? Mater. Struct.

661 Aymerich, F., Fenu, L., and Meloni, P. (2012). Effect of reinforcing wool fibres on 662 fracture and energy absorption properties of an earthen material. Constr. Build. 663 Mater. 27, 66-72.

664 Aymerich, F., Fenu, L., Francesconi, L., and Meloni, P. (2016). Fracture 665 behaviour of a fibre reinforced earthen material under static and impact flexural 666 loading. Constr. Build. Mater. 109, 109-119.

667 Bal, H., Jannot, Y., Gaye, S., and Demeurie, F. (2013). Measurement and 668 modelisation of the thermal conductivity of a wet composite porous medium: 669 Laterite based bricks with millet waste additive. Constr. Build. Mater. 41, 586670593.

671 Bouhicha, M., Aouissi, F., and Kenai, S. (2005). Performance of composite soil 672 reinforced with barley straw. Cem. Concr. Compos. 27, 617-621.

673 BS 6073 (1981). Part 1: precast concrete masonry units, Specification for precast 674 concrete masonry units.

675 Cerezo, V. (2005). Propriétés mécaniques, thermiques et acoustiques d'un

676 matériau à base de particules végétales: approche expérimentale et modélisation

677 théorique. Institut National des Sciences Appliquées. 
678 Chabannes, M., Bénézet, J.-C., Clerc, L., and Garcia-Diaz, E. (2014). Use of raw

679 rice husk as natural aggregate in a lightweight insulating concrete: An innovative 680 application. Constr. Build. Mater. 70, 428-438.

681 Chazelles, C-A de, Klein, A., and Pousthomis, N. (2011). Les cultures 682 constructives de la brique de terre crue - Echanges transdiciplinaires sur les 683 constructions en terre crue - 3 (Espérou).

684 Chee-Ming, C. (2011). Effect of natural fibres inclusion in clay bricks: Physico685 mechanical properties. Geotech. Geol. Eng. 73, 1-8.

686 Danso, H., Martinson, B., Ali, M., and Mant, C. (2015a). Performance 687 characteristics of enhanced soil blocks: a quantitative review. Build. Res. Inf. 43, $688 \quad 253-262$.

689 Danso, H., Martinson, D.B., Ali, M., and Williams, J. (2015b). Effect of fibre 690 aspect ratio on mechanical properties of soil building blocks. Constr. Build. Mater. $69183,314-319$.

692 Demir, I. (2006). An investigation on the production of construction brick with 693 processed waste tea. Build. Environ. 41, 1274-1278.

694 Demir, I. (2008). Effect of organic residues addition on the technological 695 properties of clay bricks. Waste Manag. 28, 622-627.

696 Galán-Marín, C., Rivera-Gómez, C., and Petric, J. (2010). Clay-based composite 697 stabilized with natural polymer and fibre. Constr. Build. Mater. 24, 1462-1468.

698 Ghavami, K., Toledo Filho, R.D., and Barbosa, N.P. (1999). Behaviour of 699 composite soil reinforced with natural fibres. Cem. Concr. Compos. 21, 39-48. 
700 Guinea, G.V., Planas, J., and Elices, M. (1992). Measurement of the fracture

701 energy using three-point bend tests: Part 1-Influence of experimental 702 procedures. Mater. Struct. 25, 212-218.

703 Hill, C.A.S., Khalil, H.P.S.A., and Hale, M.D. (1998). A study of the potential of

704 acetylation to improve the properties of plant fibres. Ind. Crops Prod. 8, 53-63.

705 Islam, M.., and Iwashita, K. (2006). Seismic response of fiber-reinforced and

706 stabilized adobe structures. In Proceeding of the Getty seismic adobe project

7072006 Colloquium, (Los Angeles, USA: Getty Conservation Institute).

708 Khedari, J., Watsanasathaporn, P., and Hirunlabh, J. (2005). Development of

709 fibre-based soil-cement block with low thermal conductivity. Cem. Concr.

710 Compos. 27, 111-116.

711 Kornmann, M., and Lafaurie, P. (2005). Matériaux de construction en terre cuite

712 Fabrication et propriétés (Paris: Ed. Septima).

713 Laborel-Préneron, A., Aubert, J.E., Magniont, C., Tribout, C., and Bertron, A. 714 (2016). Plant aggregates and fibers in earth construction materials: A review.

715 Constr. Build. Mater. 111, 719-734.

716 Laborel-Préneron, A., Magniont, C., and Aubert, J.-E. (2017) Characterization of 717 barley straw, hemp shiv and corn cob as resources for bioaggregate based 718 building materials. Waste Biomass Valorization, doi10.1007/s12649-017-9895-z.

719 Lenci, S., Clementi, F., and Sadowski, T. (2012). Experimental determination of 720 the fracture properties of unfired dry earth. Eng. Fract. Mech. 87, 62-72. 
721 Magniont, C. (2010). Contribution à la formulation et à la caractérisation d'un

722 écomatériau de construction à base d'agroressources. $\mathrm{PhD}$ thesis in Civil 723 Engineering. Université Toulouse III - Paul Sabatier.

724 Martins, A.P.S., Silva, F.A., and Toledo Filho, R.D. (2014). Mechanical behavior

725 of self-compacting soil-cement-sisal fiber composites. Key Eng. Mater. 634, 421726432.

727 Masonry Standards Joint Committee (MSJC) (2008). Building code requirements 728 and specification for masonry structures.

729 Mattone, R. (2005). Sisal fibre reinforced soil with cement or cactus pulp in 730 bahareque technique. Cem. Concr. Compos. 27, 611-616.

731 Millogo, Y., Morel, J.-C., Aubert, J.-E., and Ghavami, K. (2014). Experimental 732 analysis of pressed adobe blocks reinforced with Hibiscus cannabinus fibers. 733 Constr. Build. Mater. 52, 71-78.

734 Millogo, Y., Aubert, J.-E., Hamard, E., and Morel, J.-C. (2015). How properties of 735 kenaf fibers from Burkina Faso contribute to the reinforcement of earth blocks. 736 Materials 8, 2332-2345.

737 Millogo, Y., Aubert, J.-E., Séré, A.D., Fabbri, A., and Morel, J.-C. (2016). Earth

738 blocks stabilized by cow-dung. Mater. Struct. 49, 4583-4594.

739 Minke, G. (2006). Building with earth: design and technology of a sustainable 740 architecture (Basel, Switzerland).

741 Mohamed, A.E.M.K. (2013). Improvement of swelling clay properties using hay 742 fibers. Constr. Build. Mater. 38, 242-247. 
743 Morel, J.-C., Pkla, A., and Walker, P. (2007). Compressive strength testing of

744 compressed earth blocks. Constr. Build. Mater. 21, 303-309.

745 Mostafa, M., and Uddin, N. (2015). Effect of banana fibers on the compressive

746 and flexural strength of compressed earth blocks. Buildings 5, 282-296.

747 NZS 4298 Materials and workmanship for earth buildings.

748 Olivier, M., Mesbah, A., El Gharbi, Z., and Morel, J.C. (1997). Mode opératoire 749 pour la réalisation d'essais de résistance sur blocs de terre comprimée: Test 750 method for strength tests on blocks of compressed earth. Mater. Struct. 30, 515751517.

752 Palankar, N., Ravi Shankar, A.U., and Mithun, B.M. (2015). Studies on eco753 friendly concrete incorporating industrial waste as aggregates. Int. J. Sustain. 754 Built Environ. 4, 378-390.

755 Piattoni, Q., Quagliarini, E., and Lenci, S. (2011). Experimental analysis and 756 modelling of the mechanical behaviour of earthen bricks. Constr. Build. Mater. 25, $757 \quad 2067-2075$.

758 Quagliarini, E., and Lenci, S. (2010). The influence of natural stabilizers and 759 natural fibres on the mechanical properties of ancient Roman adobe bricks. J. 760 Cult. Herit. 11, 309-314.

761 Segetin, M., Jayaraman, K., and Xu, X. (2007). Harakeke reinforcement of soil762 cement building materials: Manufacturability and properties. Build. Environ. 42, $763 \quad 3066-3079$.

764 TS EN 772-1 (2002). Methods of test for mortar for masonry units - Part 1: 765 determination of compressive strength. 
766 Villamizar, M.C.N., Araque, V.S., Reyes, C.A.R., and Silva, R.S. (2012). Effect of 767 the addition of coal-ash and cassava peels on the engineering properties of 768 compressed earth blocks. Constr. Build. Mater. 36, 276-286.

769 Yetgin, Ş., Çavdar, Ö., and Çavdar, A. (2008). The effects of the fiber contents on 770 the mechanic properties of the adobes. Constr. Build. Mater. 22, 222-227. 
771 Table 1. Physicochemical properties of the plant aggregates

\begin{tabular}{|c|c|c|c|}
\hline Material & Barley straw & Hemp shiv & Corn cob \\
\hline Designation & $\mathrm{S}_{\text {short }}$ & $\mathrm{H}$ & $\mathrm{CC}$ \\
\hline Bulk density $\left(\mathrm{kg} \cdot \mathrm{m}^{-3}\right.$ ) & $57.4 \pm 1.2$ & $153.0 \pm 2.4$ & $496.8 \pm 14.0$ \\
\hline Water absorption (\%) & $414 \pm 4$ & $380 \pm 11$ & $123 \pm 2$ \\
\hline Diameter* (mm) & $2.33 \pm 1.52$ & $2.02 \pm 1.23$ & $2.63 \pm 0.43$ \\
\hline Thermal conductivity & $0.046 \pm 0.001$ & $0.053 \pm 0.002$ & $0.097 \pm 0.001$ \\
(W.m $\left.{ }^{-1} . \mathrm{K}^{-1}\right)$ & & & \\
\hline Chemical composition & & & 6.6 \\
Lignin (\%) & 5.5 & 17.2 & 41.4 \\
Cellulose (\%) & 37.7 & 50.3 & 40.7 \\
Hemicellulose (\%) & 26.7 & 17.9 & \\
\hline
\end{tabular}


773 Table 2. Mixture proportions and Proctor density of compressed specimens

\begin{tabular}{|c|c|c|c|c|c|c|c|}
\hline Reference & FWAS & S3 & S6 & H3 & H6 & CC3 & CC6 \\
\hline Plant aggregate & - & $\begin{array}{c}\text { Short } \\
\text { straw }\end{array}$ & $\begin{array}{c}\text { Short } \\
\text { straw }\end{array}$ & Hemp & $\begin{array}{c}\text { Hem } \\
p\end{array}$ & $\begin{array}{c}\text { Corn } \\
\text { cob }\end{array}$ & $\begin{array}{c}\text { Corn } \\
\text { cob }\end{array}$ \\
\hline $\begin{array}{c}\text { Plant aggregate } \\
\text { content (\%) }\end{array}$ & 0 & 3 & 6 & 3 & 6 & 3 & 6 \\
\hline $\begin{array}{c}\text { Water content (\%) } \\
774\end{array}$ & 14 & 19 & 21 & 17 & 20 & 16 & 16 \\
\hline $\begin{array}{c}\text { Dry density (kg.m } \\
3\end{array}$ & $1988 \pm$ & $1520 \pm 1$ & $1195 \pm 169$ & $1553 \pm$ & 1190 & $1877 \pm 2$ & $1704 \pm 71$ \\
\hline
\end{tabular}

775 
776 Table 3. Mixture proportions of extruded specimens

\begin{tabular}{|c|c|c|c|c|c|c|}
\hline Reference & FWAS & $\mathrm{S}_{\text {short }}$ & $\mathrm{S}_{\text {long }}$ & $\mathrm{H} 3$ & $\mathrm{~S}_{\mathrm{A} 1}$ & $\mathrm{~S}_{\mathrm{A} 2}$ \\
\hline Plant aggregate & - & $\begin{array}{c}\text { Short } \\
\text { straw }\end{array}$ & $\begin{array}{c}\text { Long } \\
\text { straw }\end{array}$ & $\mathrm{Hemp}$ & $\begin{array}{c}\text { Long } \\
\text { straw }\end{array}$ & $\begin{array}{c}\text { Long } \\
\text { straw }\end{array}$ \\
\hline $\begin{array}{c}\text { Plant aggregate content } \\
(\%)\end{array}$ & 0 & 3 & 3 & 3 & 3 & 3 \\
\hline Water content (\%) & 20 & 24 & 26 & 25 & 24 & 25 \\
\hline Surfactant & - & - & - & - & $\mathrm{A} 1$ & $\mathrm{~A} 2$ \\
\hline Dry density (kg.m $\left.{ }^{-3}\right)$ & $1982 \pm 8$ & $1781 \pm 10$ & $1734 \pm 20$ & $1712 \pm 11$ & $1784 \pm 10$ & $1782 \pm 12$ \\
\hline 77
\end{tabular}


778 Table 4. Chemical composition of the earth (LOI: Loss on Ignition)

\begin{tabular}{|c|c|c|c|c|c|c|c|c|c|c|c|}
\hline Oxides & $\mathrm{SiO}_{2}$ & $\mathrm{Al}_{2} \mathrm{O}_{3}$ & $\mathrm{Fe}_{2} \mathrm{O}_{3}$ & $\mathrm{MnO}$ & $\mathrm{MgO}$ & $\mathrm{CaO}$ & $\mathrm{Na}_{2} \mathrm{O}$ & $\mathrm{K}_{2} \mathrm{O}$ & $\mathrm{TiO}_{2}$ & $\mathrm{P}_{2} \mathrm{O}_{5}$ & $\mathrm{LOI}$ \\
\hline$\%$ & 18.73 & 7.47 & 2.39 & 0.03 & 1.27 & 35.27 & 0.09 & 0.90 & 0.39 & 0.09 & 31.92 \\
\hline
\end{tabular}

779 
Table 5. Measured mechanical properties of the materials: dry density $\left(\rho_{\text {dry }}\right)$ average compressive strength $\left(\sigma_{c}\right)$, average ultimate strain $\left(\varepsilon_{c}\right)$, average compressive strength at $1.5 \%$ strain $\left(\sigma_{c}, 1.5 \%\right)$ and average experimental Young's modulus $\left(E_{c}\right)$

\begin{tabular}{|c|c|c|c|c|c|c|}
\hline Testing protocol & Reference & $\rho_{\text {dry }}\left(\mathrm{kg} / \mathrm{m}^{3}\right)$ & $\sigma_{\mathrm{c}}(\mathrm{MPa})$ & $\varepsilon_{\mathrm{c}}(\%)$ & $\sigma_{c, 1.5 \%}(\mathrm{MPa})$ & $\mathrm{E}_{\mathrm{c}}(\mathrm{MPa})$ \\
\hline \multirow{7}{*}{ With friction } & FWAS & $1995 \pm 0$ & $4.0 \pm 0.4$ & $1.3 \pm 0.1$ & $4.0 \pm 0.4$ & $439 \pm 54$ \\
\hline & S3 & $1519 \pm 1$ & $3.3 \pm 0.2$ & $7.8 \pm 0.6$ & $0.7 \pm 0.1$ & $62 \pm 3$ \\
\hline & S6 & $1315 \pm 27$ & $3.8 \pm 0.3$ & $19.9 \pm 1.1$ & $0.4 \pm 0.0$ & $31 \pm 1$ \\
\hline & $\mathrm{H} 3$ & $1603 \pm 57$ & $2.4 \pm 0.2$ & $4.8 \pm 0.3$ & $0.7 \pm 0.1$ & $75 \pm 8$ \\
\hline & $\mathrm{H} 6$ & $1221 \pm 70$ & $1.8 \pm 0.2$ & $10.7 \pm 3.1$ & $0.4 \pm 0.1$ & $26 \pm 3$ \\
\hline & CC3 & $1878 \pm 1$ & $3.2 \pm 0.2$ & $2.4 \pm 0.2$ & $2.1 \pm 0.3$ & $217 \pm 45$ \\
\hline & $\mathrm{CC} 6$ & $1754 \pm 13$ & $1.8 \pm 0.6$ & $2.5 \pm 0.5$ & $1.3 \pm 0.6$ & $102 \pm 69$ \\
\hline \multirow{7}{*}{$\begin{array}{c}\text { Reduced } \\
\text { friction (RF) }\end{array}$} & FWAS & $1982 \pm 10$ & $3.9 \pm 0.9$ & $1.0 \pm 0.1$ & $3.9 \pm 0.9$ & $564 \pm 161$ \\
\hline & S3 & $1520 \pm 1$ & $2.1 \pm 0.2$ & $5.6 \pm 0.5$ & $0.6 \pm 0.0$ & $43 \pm 5$ \\
\hline & S6 & $1075 \pm 30$ & $3.6 \pm 0.2$ & $17.2 \pm 1.5$ & $0.3 \pm 0.0$ & $25 \pm 0$ \\
\hline & $\mathrm{H} 3$ & $1504 \pm 54$ & $1.6 \pm 0.1$ & $3.6 \pm 0.3$ & $0.7 \pm 0.1$ & $51 \pm 5$ \\
\hline & $\mathrm{H} 6$ & $1159 \pm 41$ & $1.5 \pm 0.1$ & $7.5 \pm 1.1$ & $0.4 \pm 0.0$ & $22 \pm 1$ \\
\hline & $\mathrm{CC} 3$ & $1876 \pm 1$ & $1.3 \pm 0.1$ & $1.2 \pm 0.1$ & $1.3 \pm 0.1$ & $136 \pm 40$ \\
\hline & CC6 & $1654 \pm 53$ & $1.0 \pm 0.1$ & $1.8 \pm 0.2$ & $0.9 \pm 0.0$ & $69 \pm 9$ \\
\hline
\end{tabular}

783 
785 Table 6. Average experimental mechanical properties: dry density $\left(\rho_{\text {dry }}\right)$, flexural strength $\left(\sigma_{f}\right)$,

786 ultimate strain $\left(\varepsilon_{f}\right)$, experimental Young's modulus $\left(E_{f}\right)$ and fracture energy $\left(G_{f}\right)$

\begin{tabular}{|c|c|c|c|c|c|c|}
\hline Type & $\rho_{\text {dry }}\left(\mathrm{kg} \cdot \mathrm{m}^{-3}\right)$ & $\mathrm{F}(\mathrm{N})$ & $\sigma_{f}(\mathrm{MPa})$ & $\varepsilon_{f}(\%)$ & $\mathrm{E}_{f}(\mathrm{MPa})$ & $\mathrm{G}_{f}\left(\mathrm{~J} \cdot \mathrm{m}^{-2}\right)$ \\
\hline FWAS & $1982 \pm 8$ & $2053 \pm 120$ & $1.88 \pm 0.10$ & $0.22 \pm 0.02$ & $856 \pm 57$ & $7 \pm 0$ \\
\hline $\mathrm{S}_{\text {short }}$ & $1781 \pm 10$ & $1900 \pm 123$ & $1.80 \pm 0.13$ & $0.44 \pm 0.11$ & $475 \pm 49$ & $296 \pm 50$ \\
\hline $\mathrm{S} 3_{\text {long }}$ & $1734 \pm 20$ & $1776 \pm 135$ & $1.69 \pm 0.14$ & $0.55 \pm 0.14$ & $385 \pm 29$ & $484 \pm 41$ \\
\hline $\mathrm{H} 3$ & $1712 \pm 11$ & $1453 \pm 86$ & $1.34 \pm 0.08$ & $0.31 \pm 0.04$ & $577 \pm 72$ & $157 \pm 9$ \\
\hline $\mathrm{S}_{\mathrm{A} 1}$ & $1784 \pm 10$ & $1798 \pm 163$ & $1.69 \pm 0.16$ & $0.49 \pm 0.03$ & $442 \pm 72$ & $462 \pm 11$ \\
\hline $\mathrm{S}_{\mathrm{A} 2}$ & $1782 \pm 12$ & $1824 \pm 183$ & $1.73 \pm 0.10$ & $0.36 \pm 0.08$ & $508 \pm 67$ & $538 \pm 81$ \\
\hline
\end{tabular}


789 Figure 1. Compressed specimens of FWAS (a) and S6 (b)

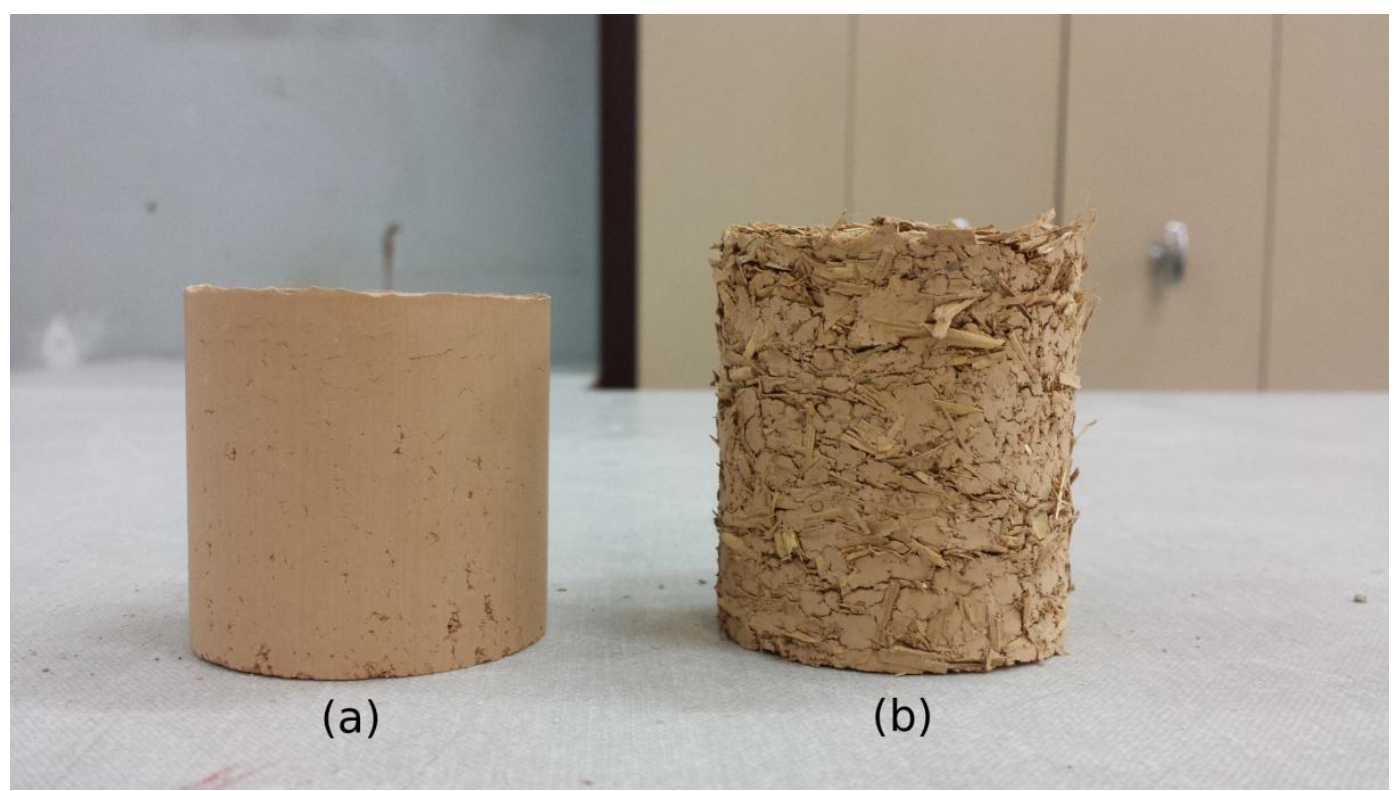

790

791 
792 Figure 2. Vacuum extruder

793

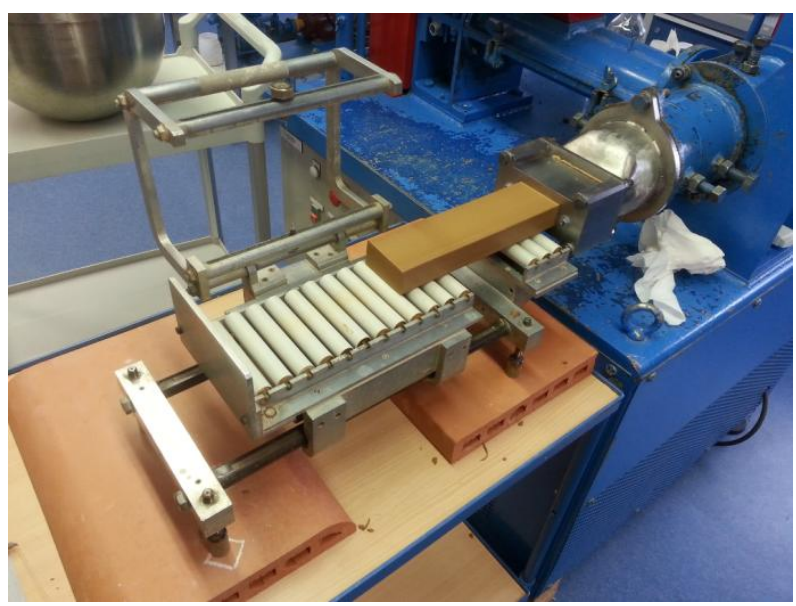


794 Figure 3. Compressive test method: (a) with friction and (b) with reduced friction

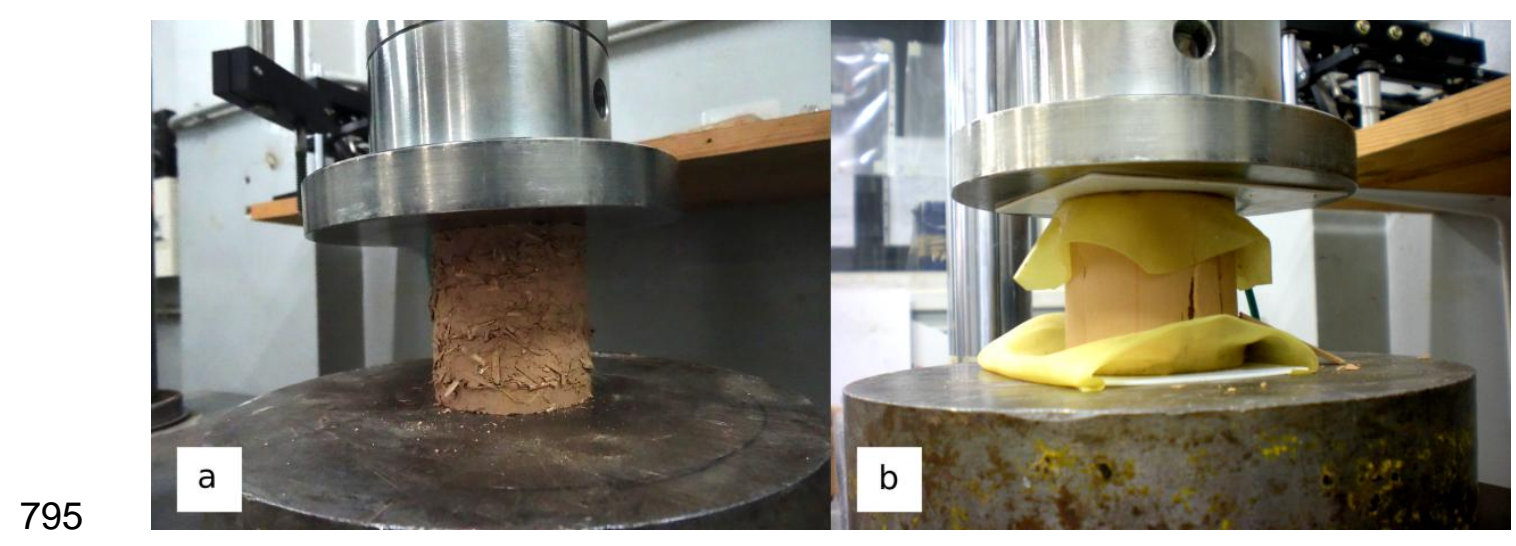


Figure 4. Flexural test set up

797
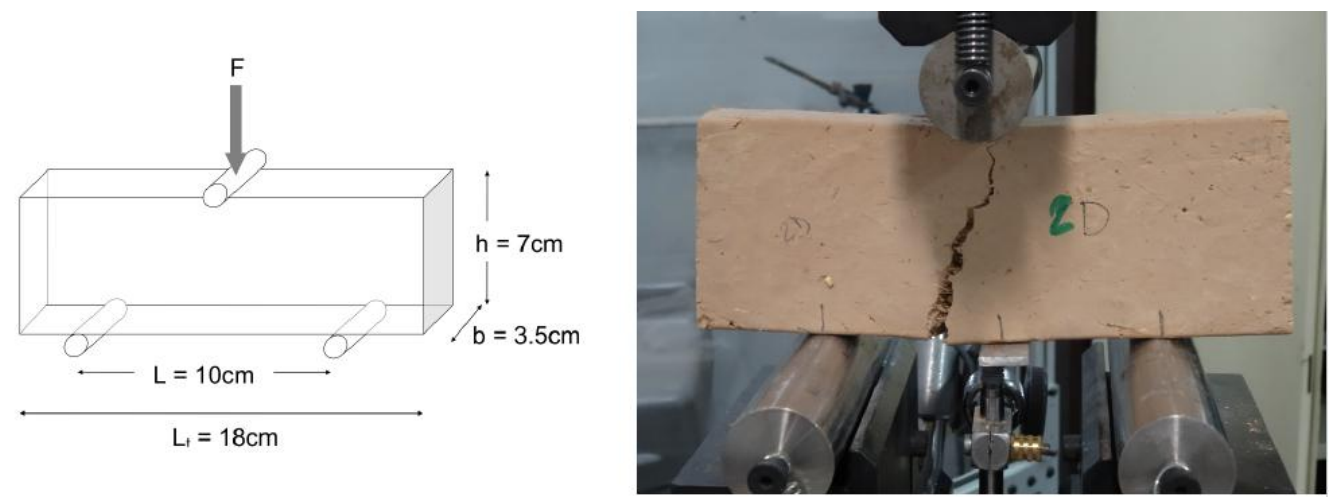

798 
799 Figure 5. Comparative grain size distribution curve for earth: FWAS and standard

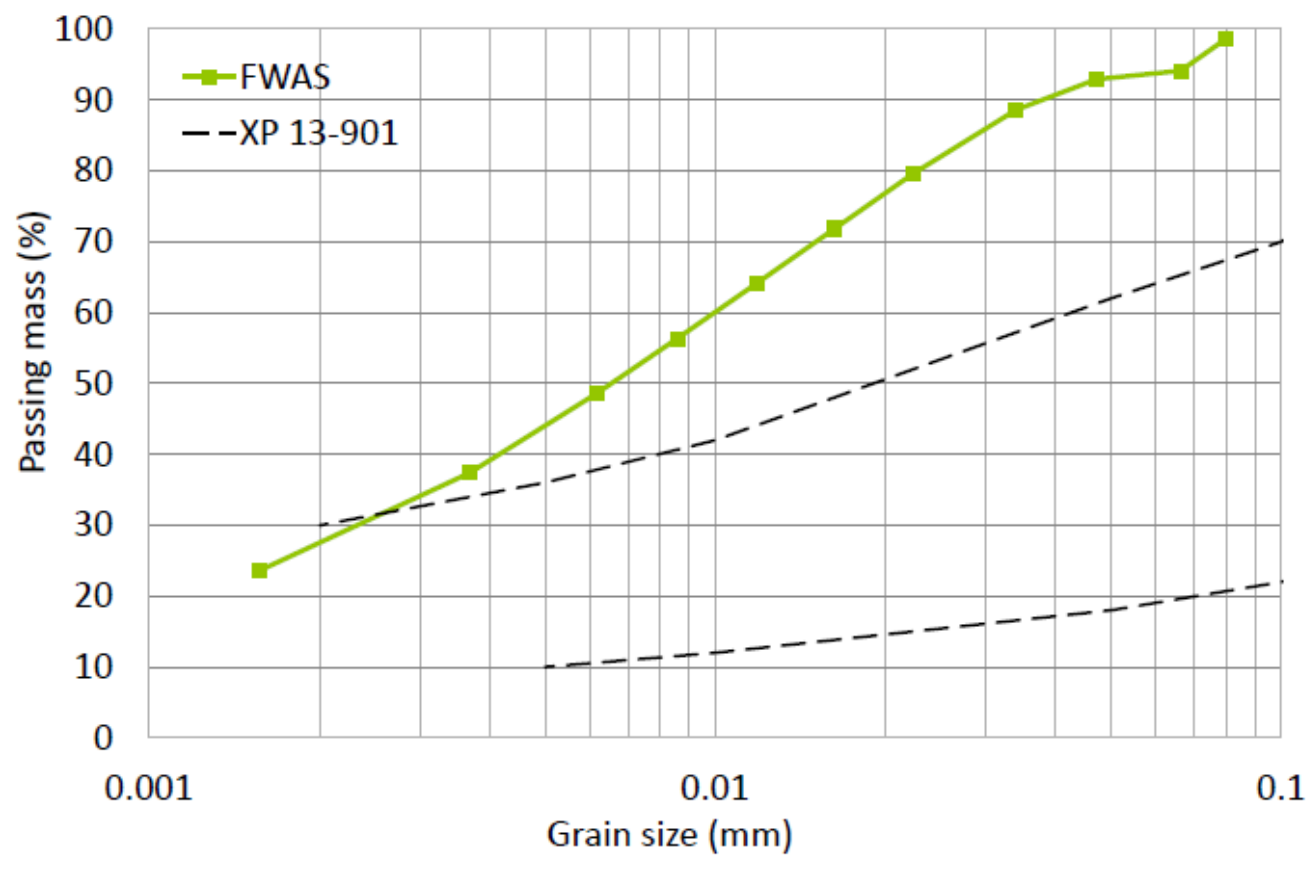

800

801 
802 Figure 6. X-ray diffraction pattern of the earth.

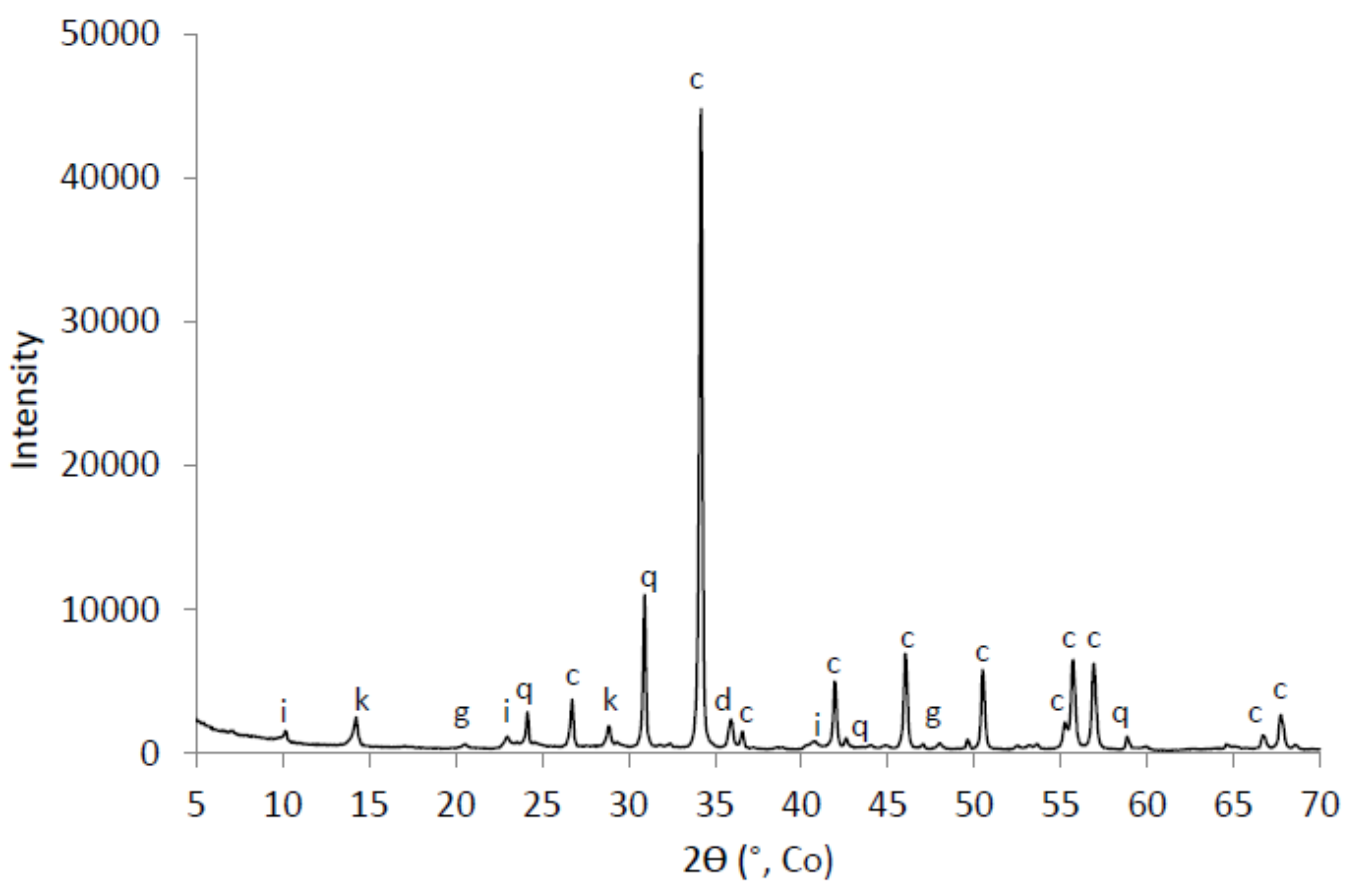


805 Figure 7. TG and DTG (Derivative Thermo-Gravimetric) curves of the earth

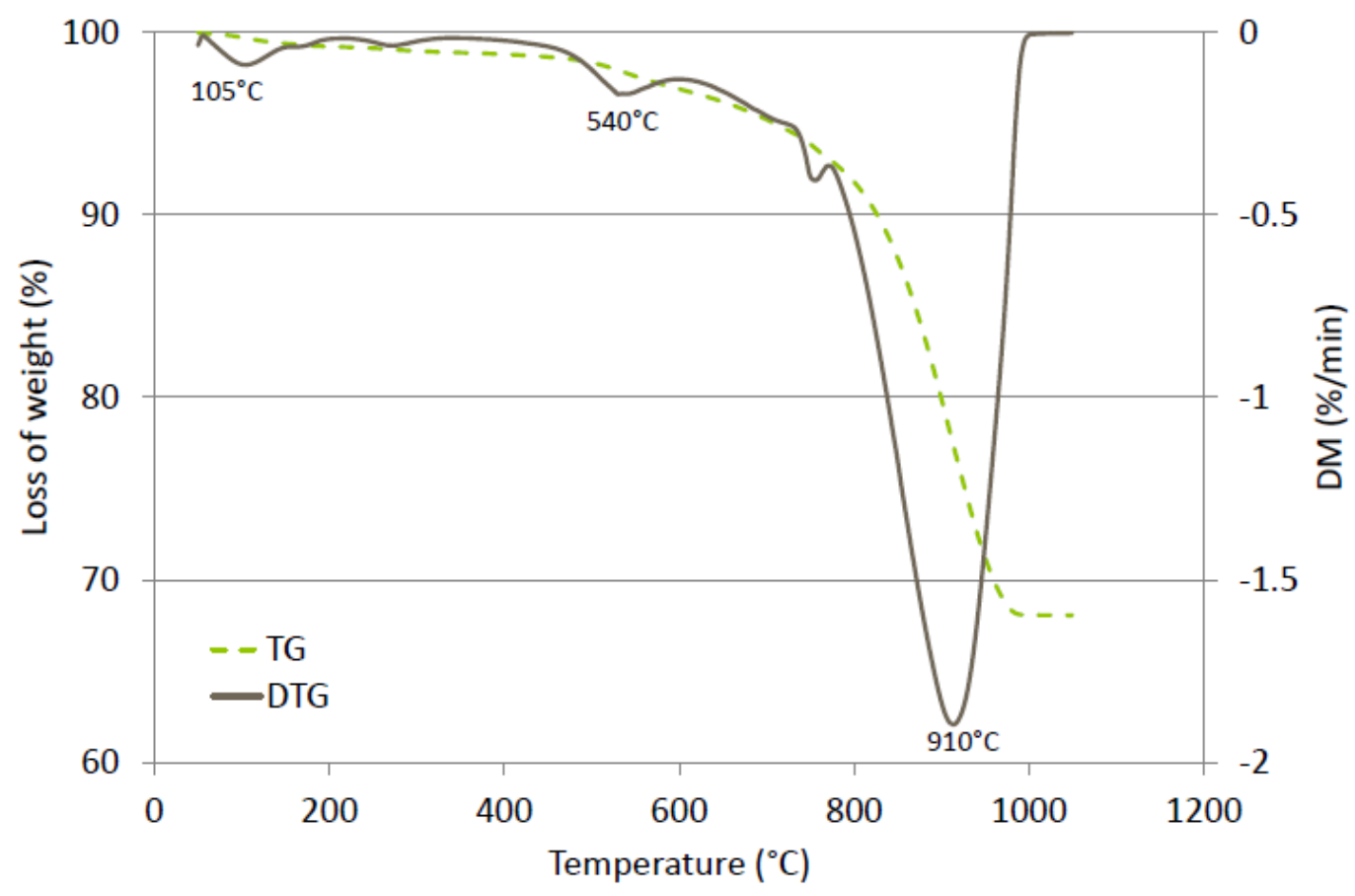

807 
808 Figure 8. Bulk density as a function of the plant aggregate content

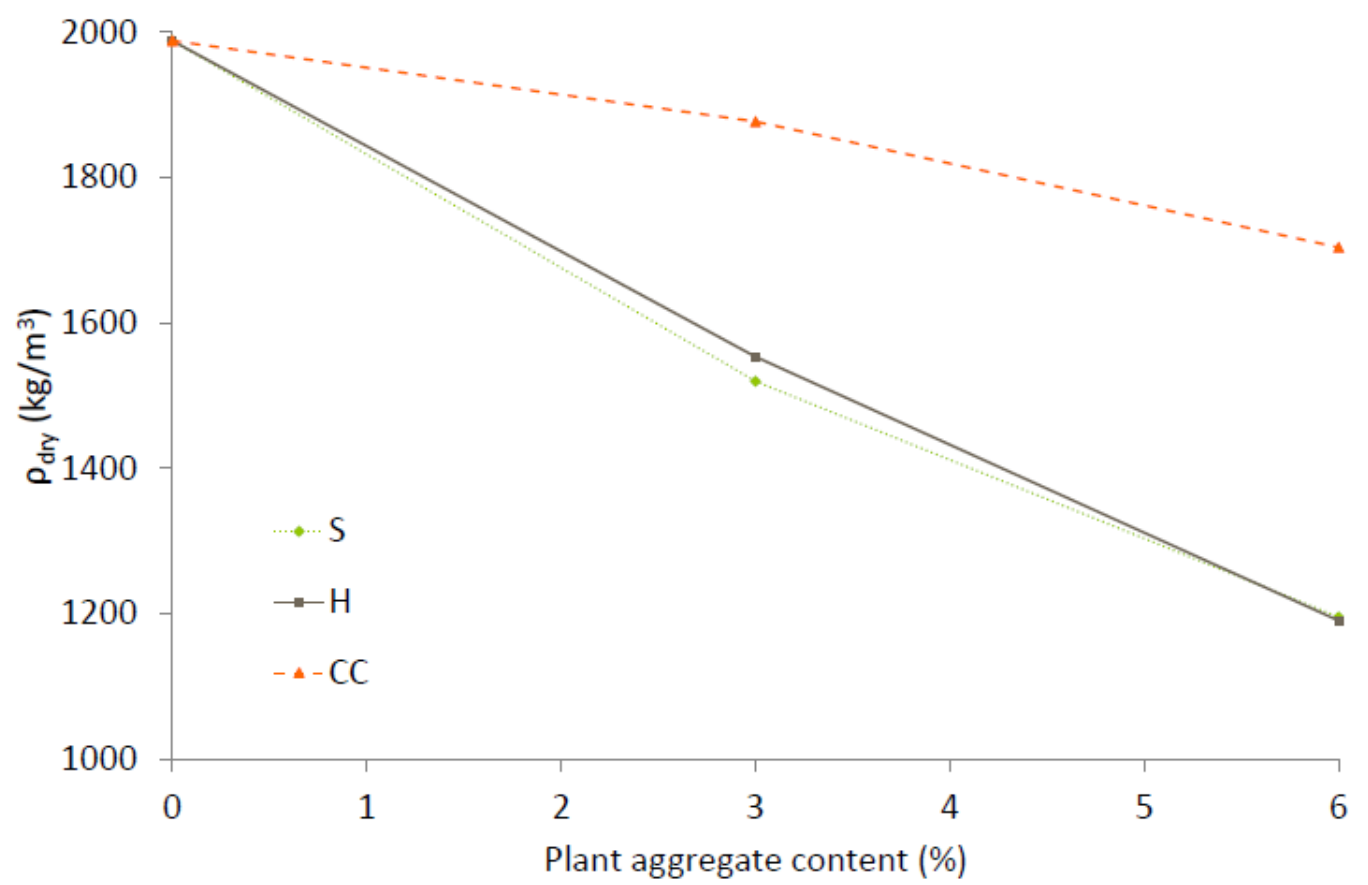

809

810 
811 Figure 9. Compressive strength of the mixtures according to the testing protocol

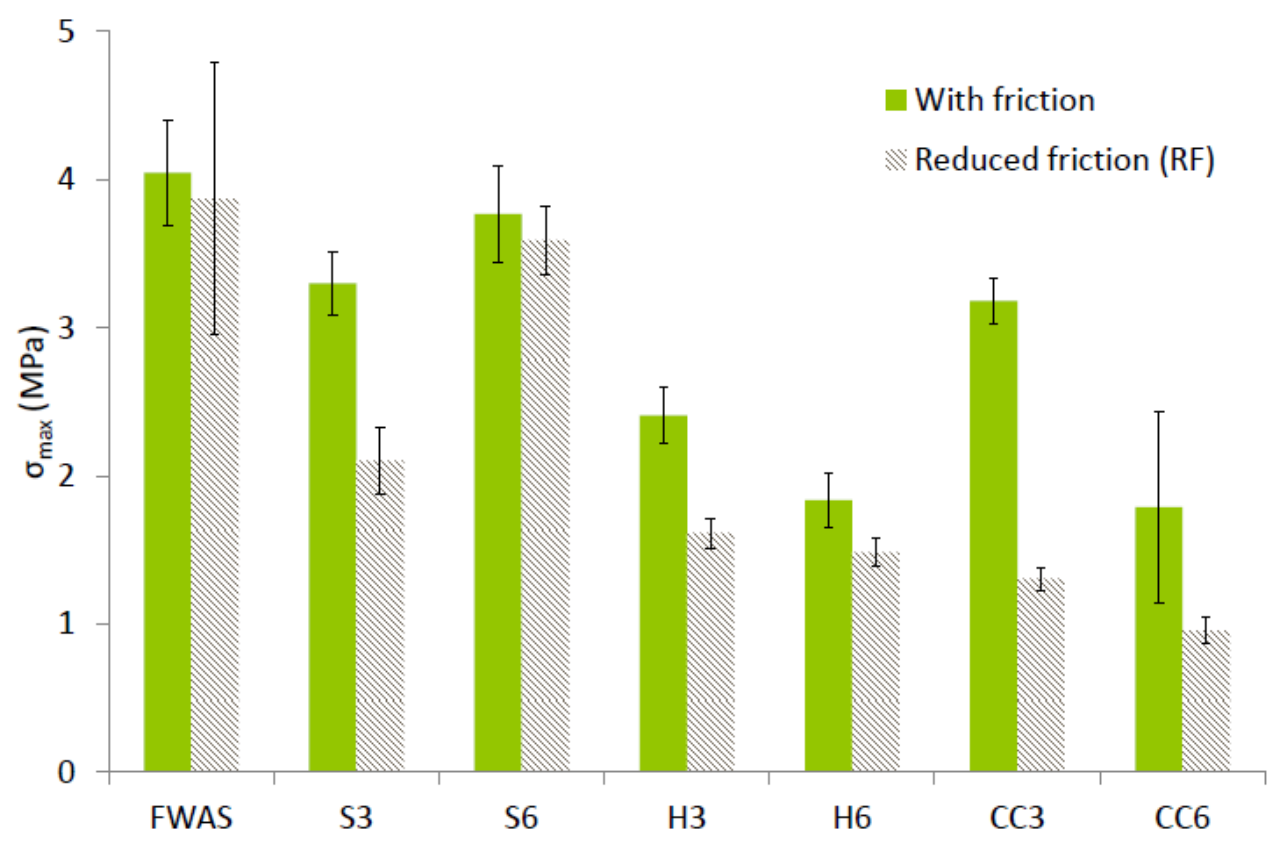

812

813 
814 Figure 10. Results for compressive strength test with friction

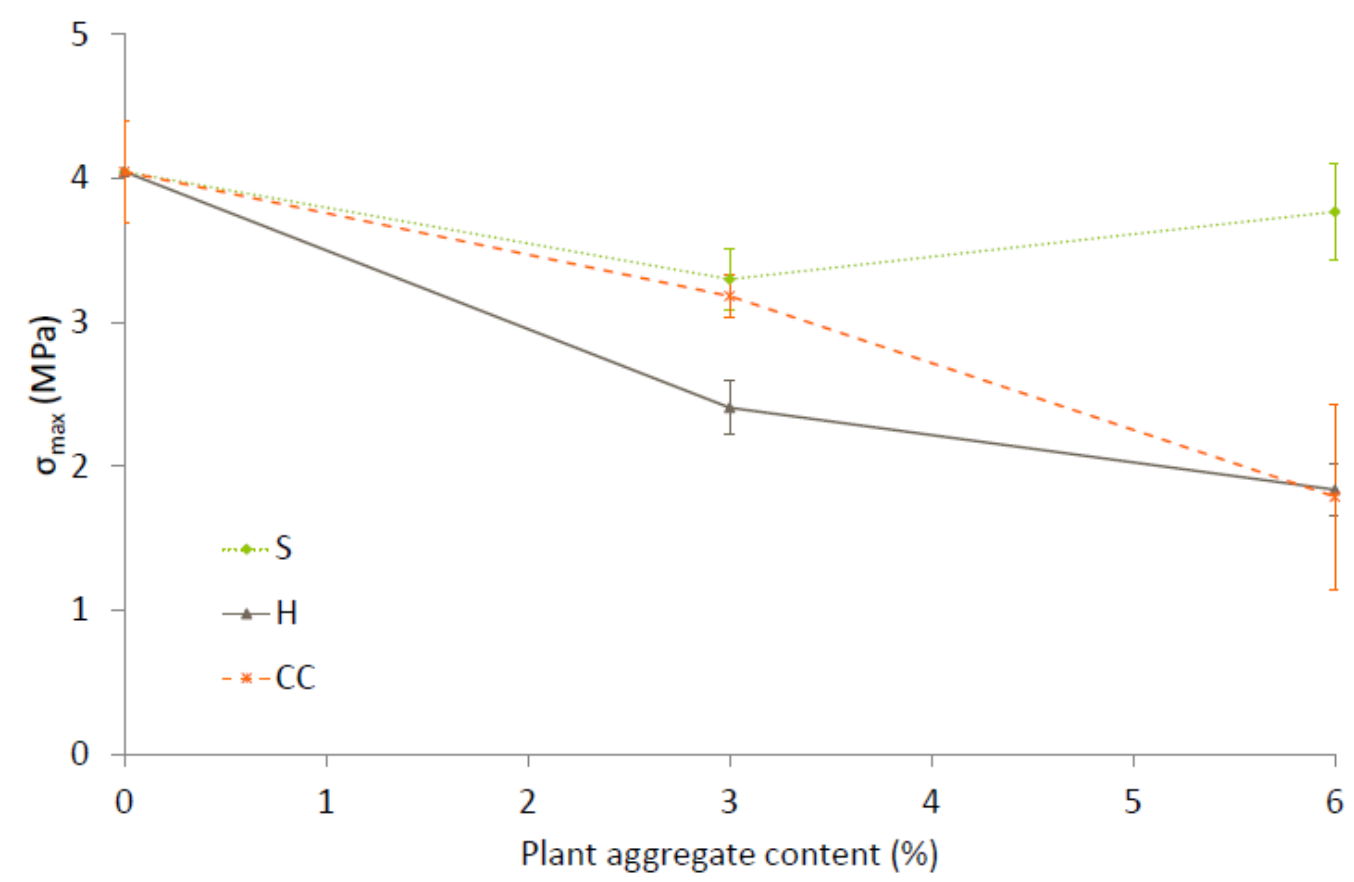

815

816 
817 Figure 11. Strain-stress diagram for all the specimens

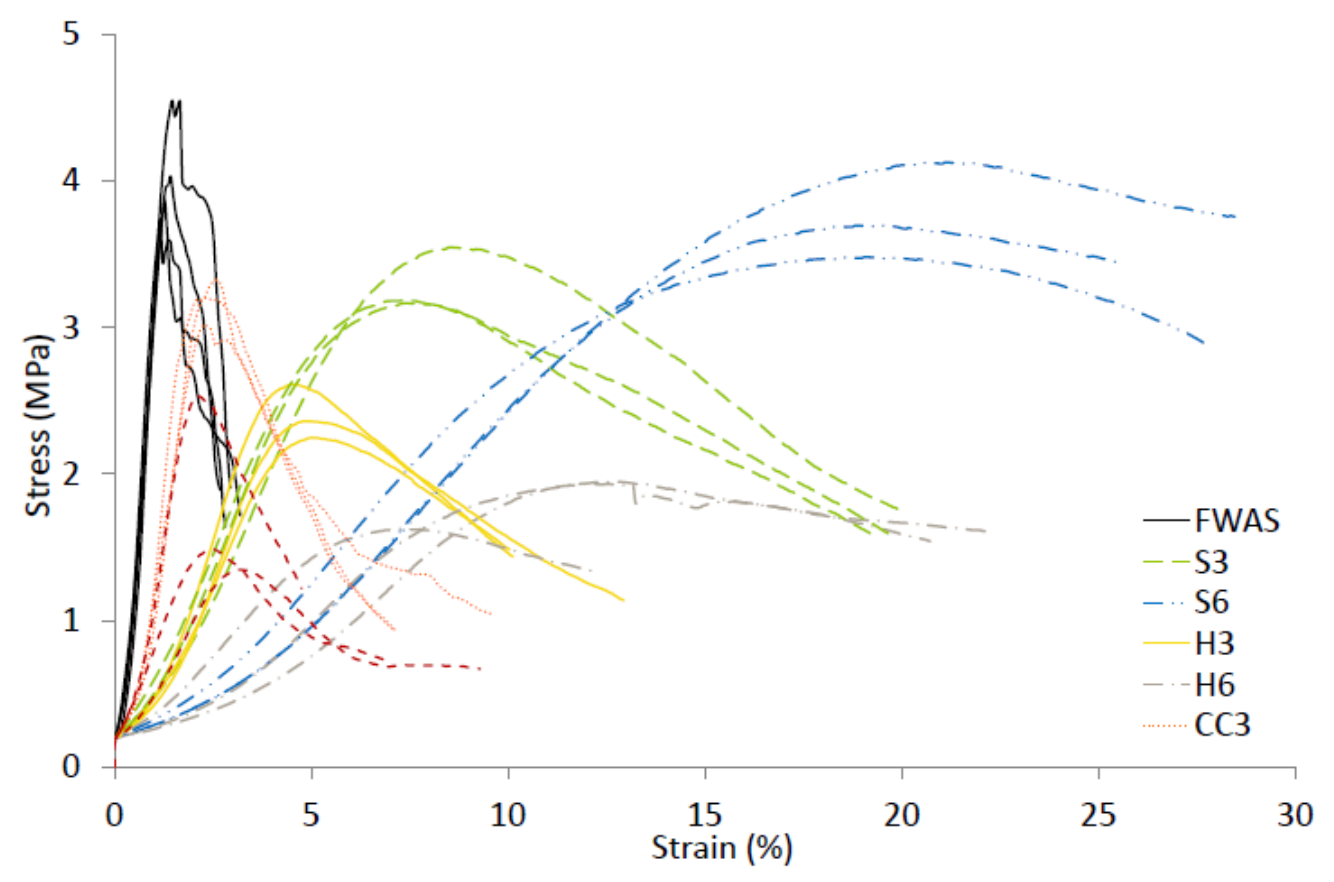

818

819 
820 Figure 12. Maximum compressive strength $\left(\sigma_{c}\right)$ and compressive strength at $821 \quad 1.5 \%$ strain $\left(\sigma_{c, 1.5} \%\right)$

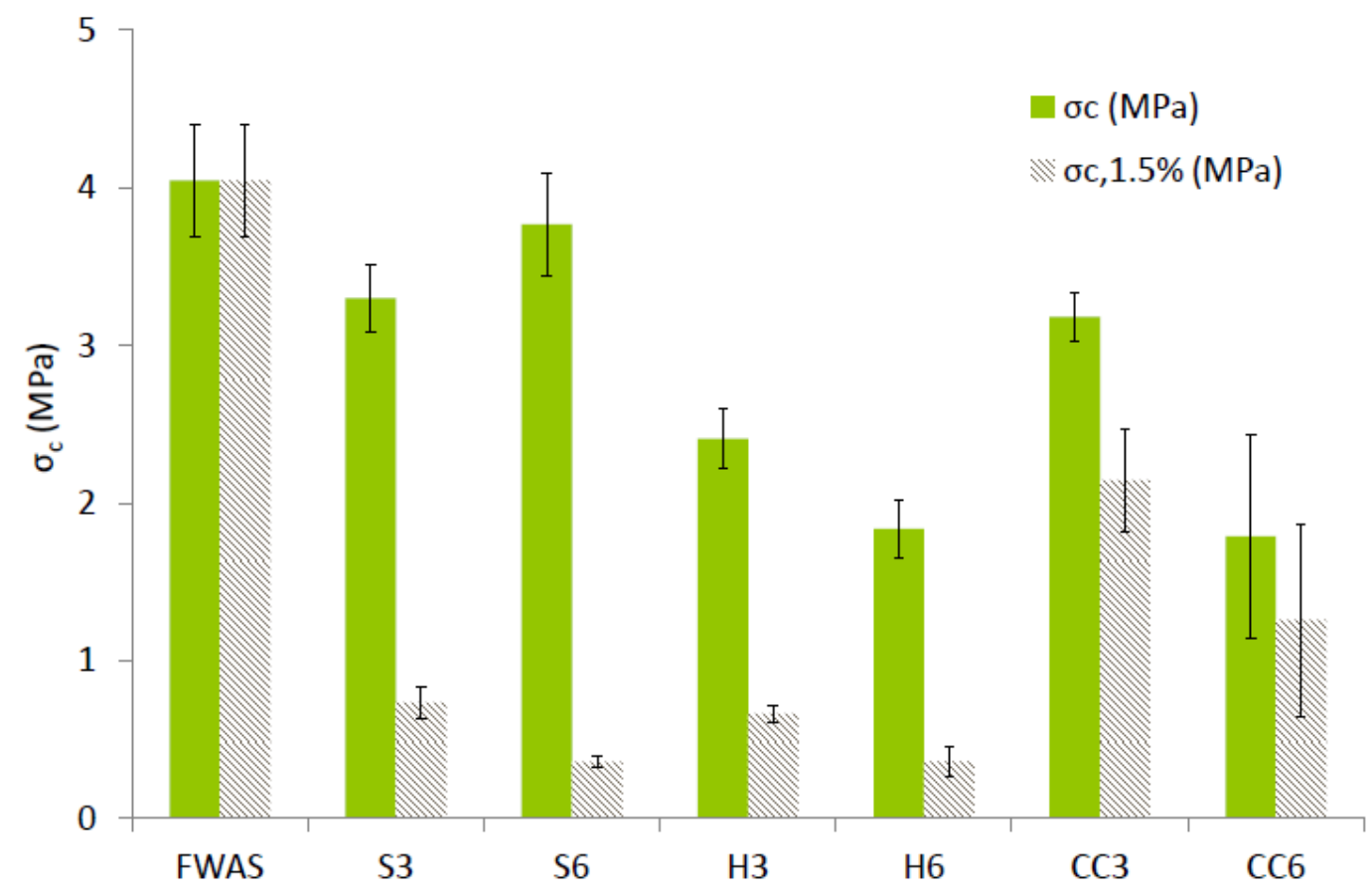

822

823 
824 Figure 13. Young's moduli of the materials for both protocols

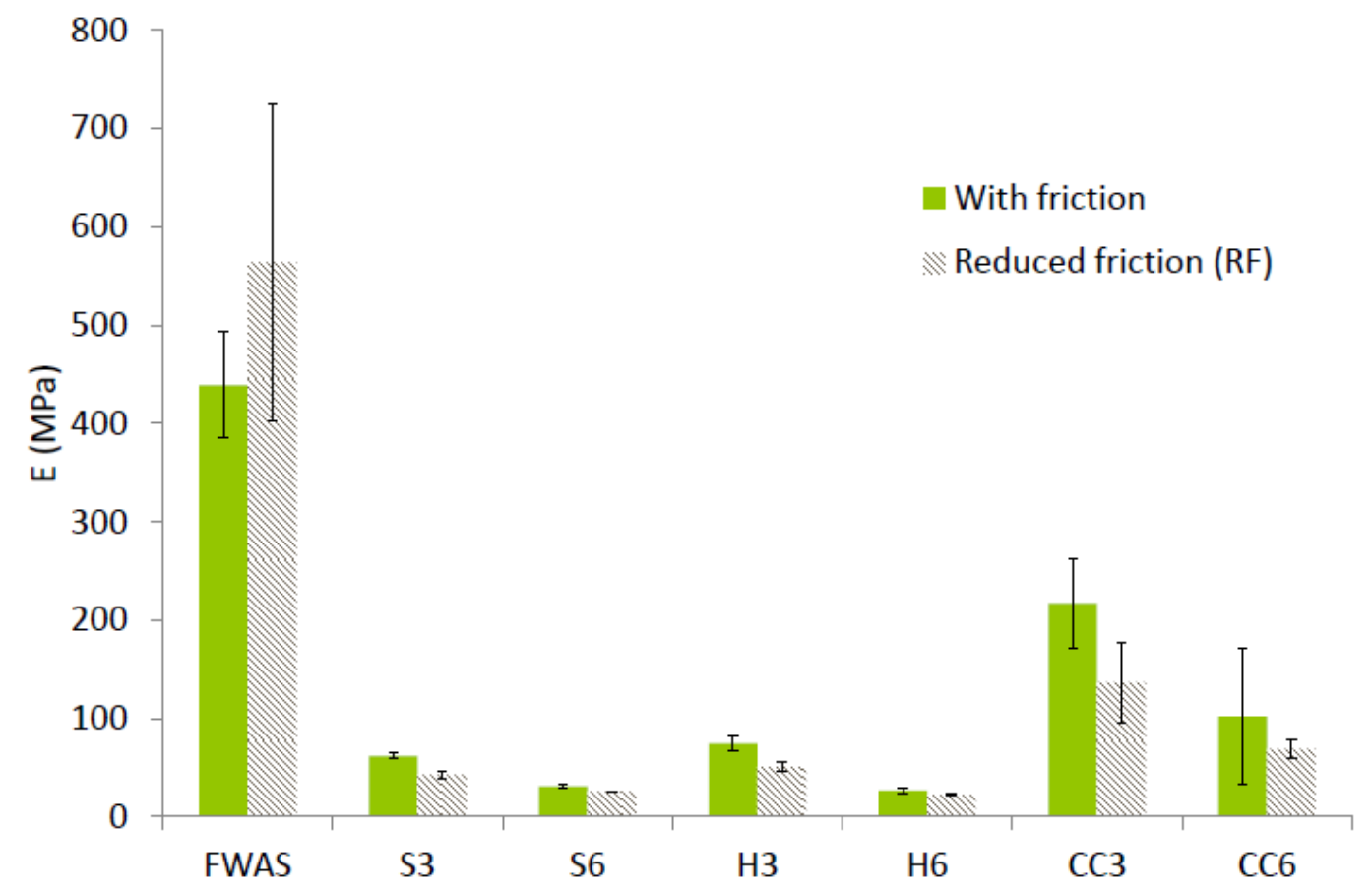


827 Figure 14. Young's modulus from compressive test as a function of the plant 828 aggregate content

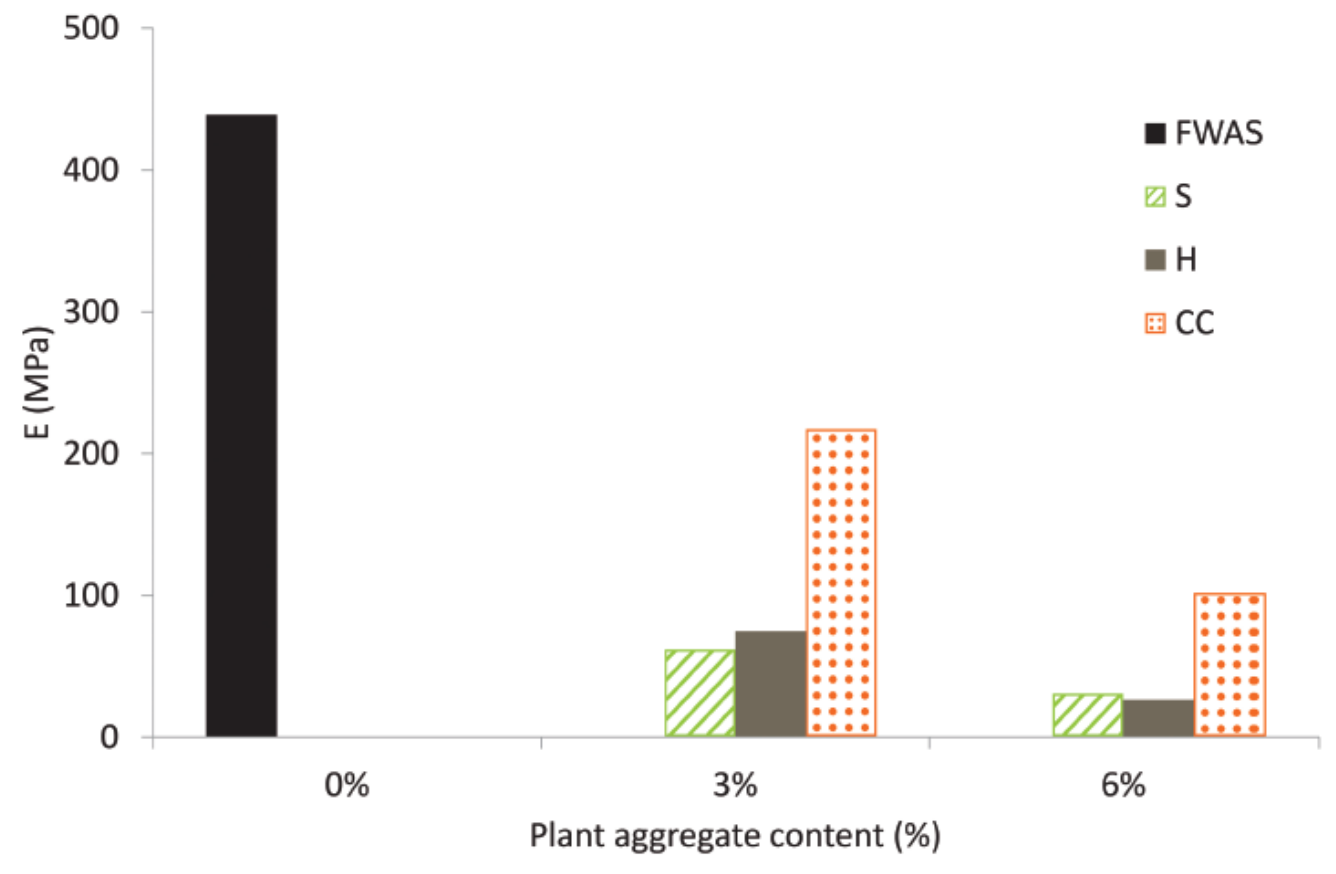

829

830 
831 Figure 15. Young's modulus as a function of the density

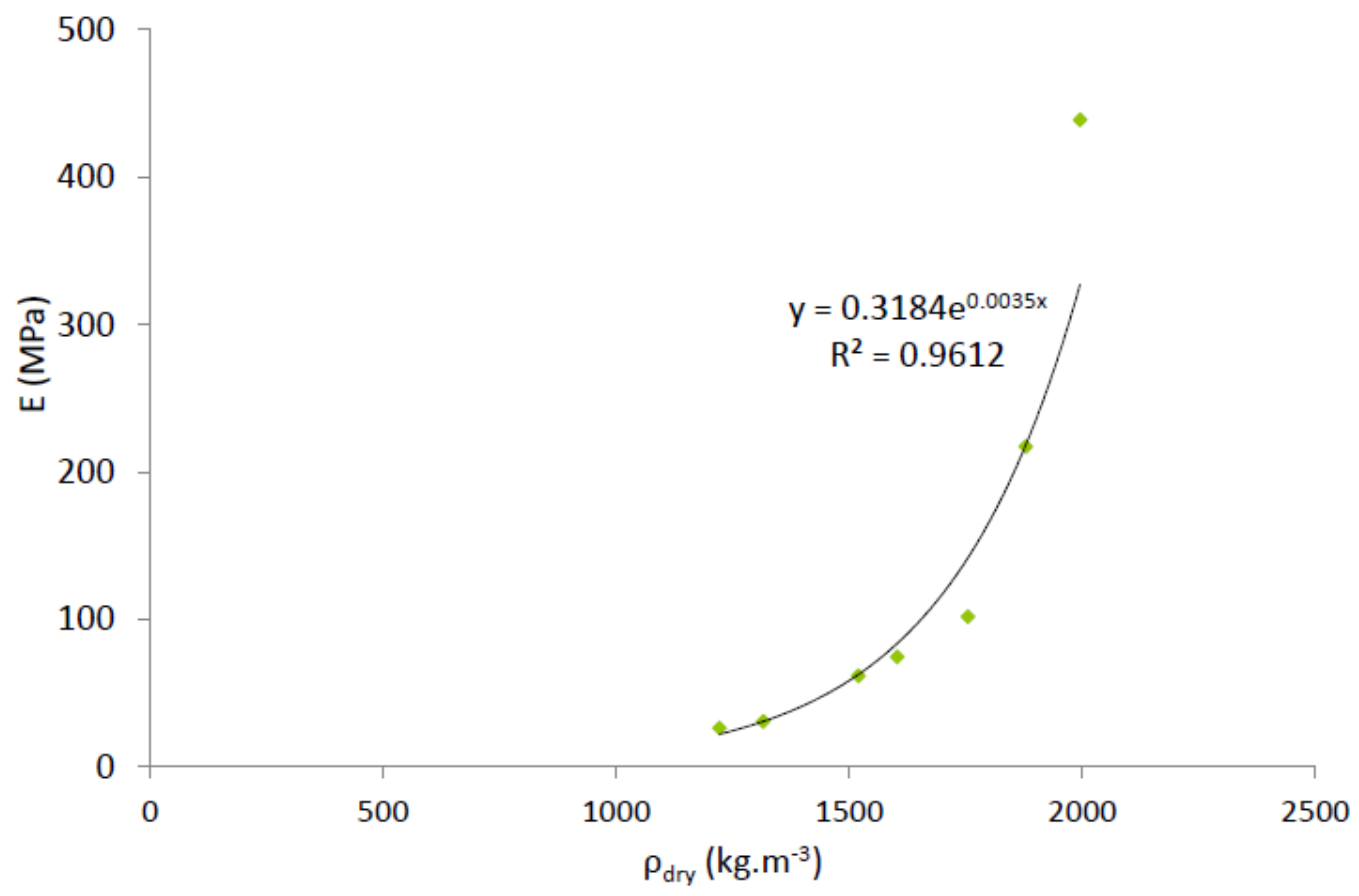


834 Figure 16. Influence of the plant aggregate on flexural behavior: (a) Flexural load835 carrying capacity, (b) Peak strain $\left(\varepsilon_{\mathrm{f}}\right)$, (c) Average fracture energy $\left(G_{\mathrm{f}}\right)$ and $(\mathrm{d})$ 836 Young's modulus
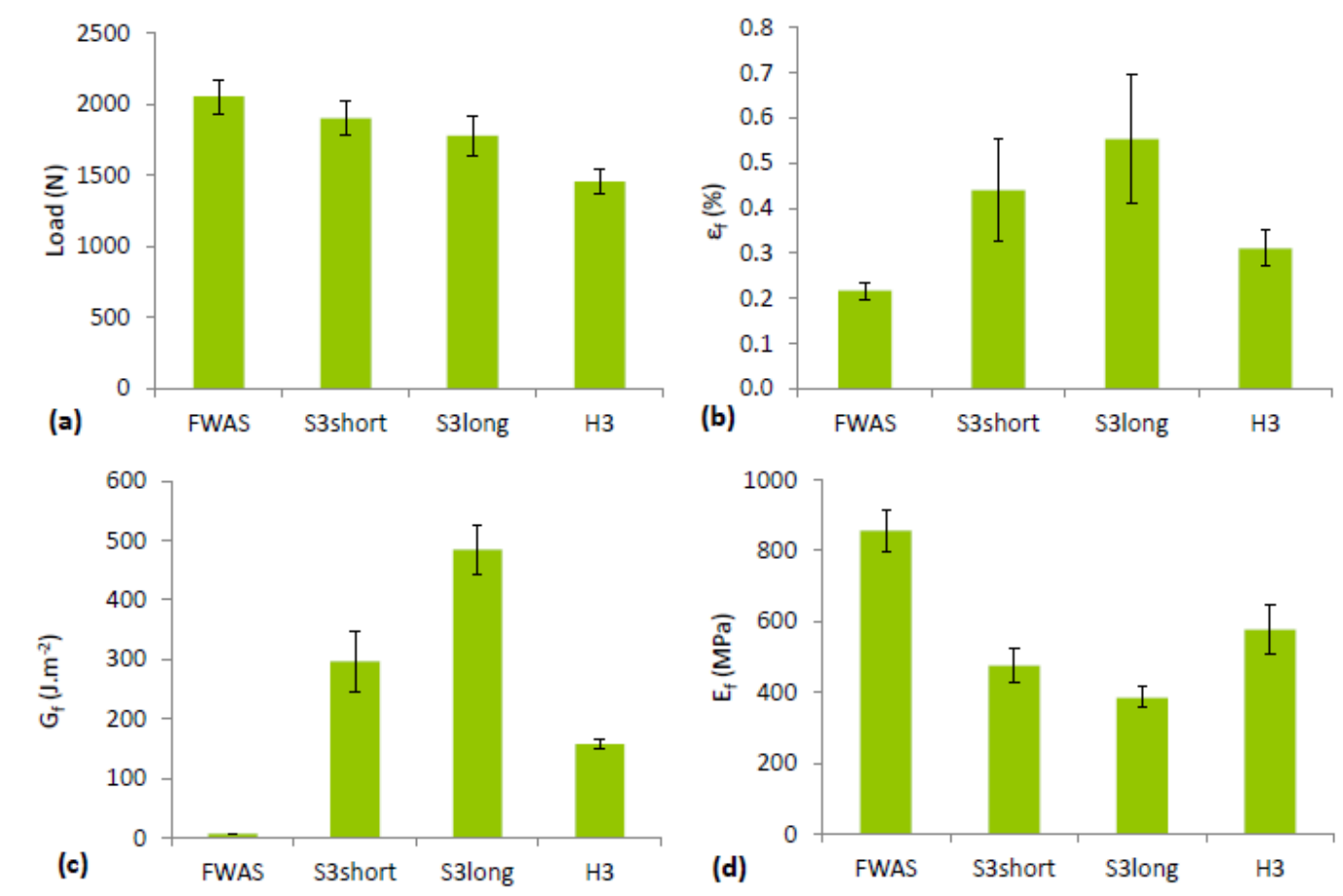
839 Figure 17. Typical load-deflection curves

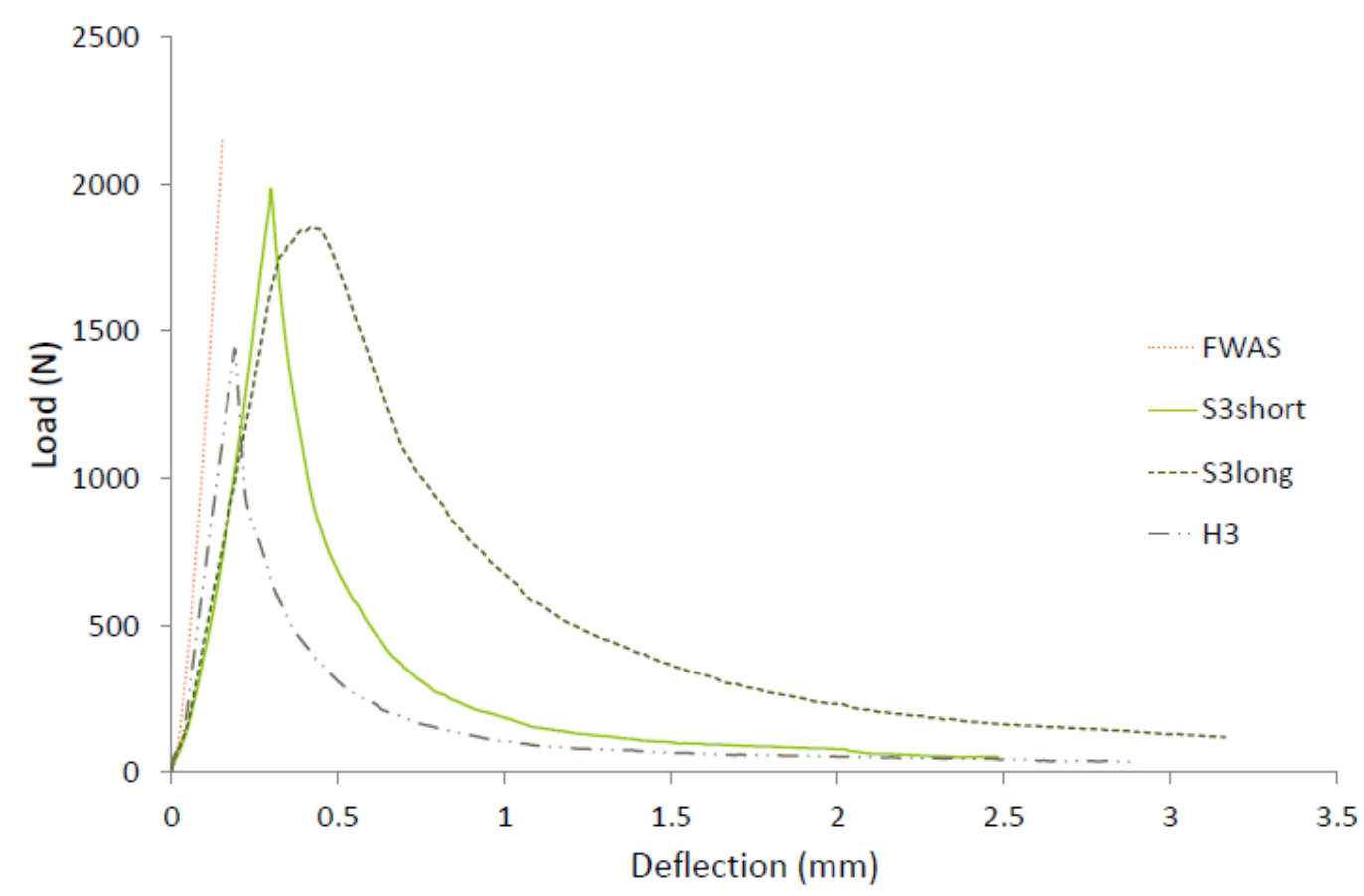

840

841 
842 Figure 18. Influence of the surfactants on flexural behavior: (a) Flexural load-

843 carrying capacity, (b) Peak strain (£f), (c) Average fracture energy (Gf) and (d)

844 Young's modulus
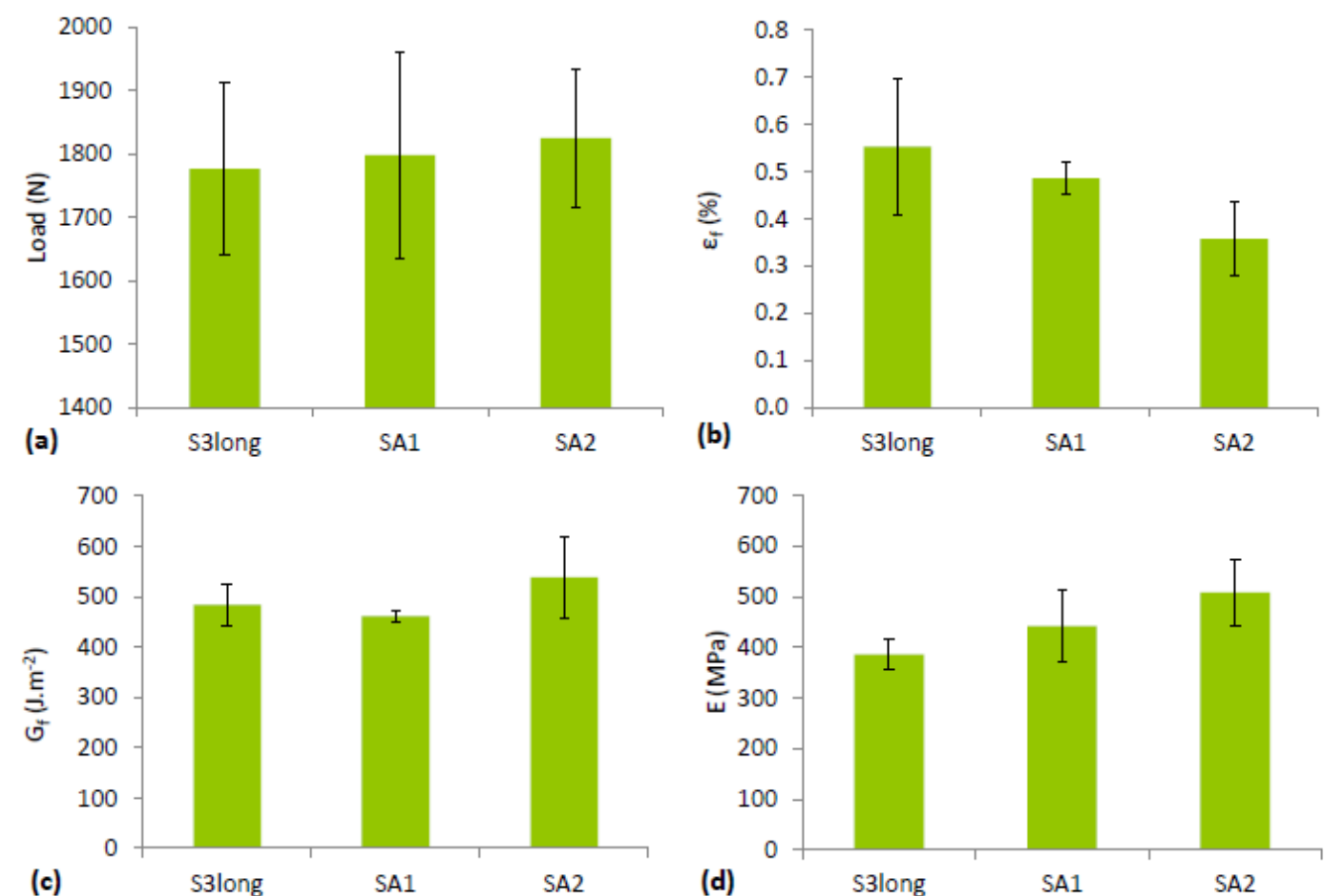

845 